\title{
LA PRESERVACIÓN Y PROTECCIÓN DEL PATRIMONIO CULTURAL DEL PERÚ EN EL MARCO DE LA CONVENCIÓN DEL PATRIMONIO MUNDIAL
}

\author{
THE PRESERVATION AND PROTECTION OF THE CULTURAL \\ HERITAGE OF PERU IN THE FRAMEWORK OF THE WORLD \\ HERITAGE CONVENTION
}

\author{
Manuel Rodríguez Cuadros \\ Ministerio de Relaciones Exteriores del Perú
}

\section{RESUMEN}

Se presenta una visión detallada del sistema de protección del patrimonio cultural y natural de la humanidad, sus principios, mecanismos y cursos de acción. Asimismo, se analiza las obligaciones y responsabilidades asumidas por el Perú y los demás Estados que forman parte de la Convención de 1972; se explica que el sistema es esencialmente jurídico, pues más allá de los componentes arqueológicos, arquitectónicos, antropológicos, geográficos, históricos y etnohistóricos que conlleva la noción de patrimonio cultural, su protección está regulada y orientada por normas jurídicas de una doble vertiente: aquellas que forman parte strictu sensu de la legislación nacional y las contenidas en los tratados internacionales. Ambas exigibles en el derecho interno. Al evaluar la aplicación del sistema a los bienes peruanos inscritos en la Lista del Patrimonio Mundial (LPM), se utiliza como caso de estudio la situación de Machu Picchu, explicando las fortalezas y vulnerabilidades del modelo de gestión.

Palabras clave: patrimonio de la humanidad, sistema de protección, bienes culturales y naturales, protección del patrimonio del Perú, valor universal excepcional, Lista del Patrimonio Mundial, Lista en peligro, Santuario de Machu Picchu.

\begin{abstract}
The article presents a detailed vision of the system for the protection of the cultural and natural heritage of humanity, its principles, mechanisms and courses of action. It analyzes the obligations and responsibilities assumed by Peru and the other States that are part of the 1972 Convention. It explains that the system is essentially legal, because beyond the archaeological, architectural, anthropological, geographic, historical and ethnohistorical components that entails the notion of cultural heritage, its protection is regulated and guided by legal norms of a
\end{abstract}

Este es un artículo Open Access bajo la licencia Creative Commons AtribuciónNoComercial-Compartirlgual 4.0

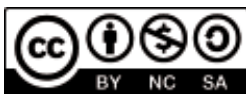


double aspect: those that form a strictu sensu part of the national legislation and those contained in international treaties. Both required in domestic law. When evaluating the application of the system to Peruvian goods inscribed in the world heritage list, the author uses the situation of Machu Picchu as a case study and explains the strengths and vulnerabilities of its management model.

Keywords: World Heritage. Protection system. Cultural and natural assets. Protection of peruvian heritage. Exceptional Universal Value. World Heritage List. List in danger. Sanctuary of Machu Picchu.

Hay varias maneras de ver el mapa del Perú. Las imágenes de la geografía y la división política son las más usuales y comunes. Muestran de alguna manera lo obvio. Hay imágenes más heterodoxas de la cartografía peruana. La de la densidad de la población, por ejemplo. Allí se nota dramáticamente el desequilibrio físicosocial del Perú. Cerca de un tercio de la población (28.93\%) vive en la provincia de Lima, un espacio que solo es el $0.22 \%$ del territorio nacional $\left(2811.65 \mathrm{~km}^{2}\right)$. Otros mapas dicen mucho sobre la riqueza del Perú como territorio y como sociedad. El de los recursos mineros cubre casi todo el territorio de la costa y de la sierra. Más del 14\% del territorio está concesionado a empresas mineras.

Pero hay un mapa que sí cubre todo el territorio nacional, y en el que no existe un desequilibrio físicocultural. Es el mapa de las áreas arqueológicas y sitios del patrimonio cultural, material, inmaterial y natural. La riqueza del patrimonio cultural peruano está presente con una densidad intensa en todo el territorio nacional. Porque allí donde no existe población, están los paisajes y parques naturales que forman parte de ese patrimonio.

El Perú es origen y escenario de la evolución de una de las seis civilizaciones más importantes de la humanidad. El desarrollo paralelo y los espacios de sincretismo de su cultura inmaterial originaria con los elementos europeos y occidentales han producido una diversidad cultural solo comparable con su diversidad biológica. De las 117 zonas de vida reconocidas en el mundo, 84 se encuentran en el Perú. Por ello, es uno de los 15 países del mundo de megadiversidad a nivel global. Patrimonio cultural y patrimonio natural no solo son en la historia de la sociedad peruana el marco de referencia en el que la vida individual y social de los peruanos transcurre desde hace más de cuatro mil años de alta cultura, sino elementos esenciales de la historia, la identidad y la conciencia social y nacional de la población.

Esta riqueza y diversidad cultural y natural constituyen a la vez los recursos turísticos del país. Aunque, por lo general, no se explicita ni reconoce, el turismo en el Perú es una actividad económica enteramente derivada del patrimonio cultural y natural. Los recursos turísticos del Perú son casi al 100\% patrimonio cultural y patrimonio natural. Por ello, las políticas públicas de turismo y de cultura deberían elaborarse y ejecutarse de manera integrada. Con un enfoque sostenible que asegure que estos recursos sean conservados y protegidos y que puedan transmitirse de generación en generación.

El Perú es un Estado y una sociedad que tiene como uno de sus más importantes y competitivos atributos, su patrimonio cultural y la biodiversidad de su medio geográfico. En el antiguo Perú florecieron -en plural- un conjunto de sociedades y culturas que alrededor de los 4000 años a. C. se constituyeron en una de las cinco 
grandes civilizaciones de la historia de la humanidad. Durante todo el proceso de evolución histórica de la civilización andina, la pluralidad de sociedades políticas desarrolló diversas expresiones culturales, cuyas expresiones materiales e inmateriales han sido puestas en valor por la arqueología, la antropología, la etnohistoria y la historia. Durante la Colonia y la República este acervo fue objeto de procesos de sincretismo y yuxtaposición con los valores y las expresiones culturales y espirituales venidas de Europa. El patrimonio material se ha enriquecido en todo este proceso de evolución y consolidación de la cultura peruana, cuyo signo distintivo sigue siendo su diversidad y pluralidad. Ese patrimonio se expresa hoy en conjuntos arqueológicos, edificaciones y centros urbanos, representativos de todas las etapas de la historia nacional, en un número y valor que no los posee ningún país en las Américas.

Al mismo tiempo, la diversidad étnica y cultural, sobre bases regionales y locales, desde las antiguas civilizaciones andinas hasta nuestros días, han creado en la historia acumulada del mundo andino, la Colonia y la República, una vasta multiplicidad de expresiones de cultura inmaterial: usos, representaciones, expresiones, danzas, mitos, cosmovisiones, conocimientos y técnicas, que comprenden, entre otras, las tradiciones orales, las artes del espectáculo, los rituales y eventos festivos, los conocimientos y prácticas relativos a la naturaleza y el universo, las expresiones espirituales religiosas, las técnicas y conocimientos tradicionales.

El patrimonio cultural, material e inmaterial, sin embargo, no es solo la expresión de la riqueza cultural diversa del Perú. Es también un factor identitario, en el que comunidades locales, pueblos y regiones afirman y recrean su propia historia y sus sentimientos de pertenencia y cohesión subjetiva y social. La vivencia y el sentimiento de pertenencia respecto a sus creaciones contribuye a la identificación con su patrimonio cultural. Y ello genera un sentimiento de orgullo, de dignidad, respecto de su propia historia. Se crean así las condiciones para la retransmisión del patrimonio entre las diversas generaciones. El Perú es uno de los países del mundo con una cultura tradicional y viva más diversa.

En el exterior, a través de los siglos, se ha afirmado esta visión del Perú como un centro de antiguas civilizaciones y un epicentro múltiple y dinámico de expresiones culturales tradicionales que se mantienen y desarrollan en el tiempo, y que se expresan en las diversas regiones del país como cultura viva y actual. La marca Perú -más allá de coyunturales estrategias de marketing- en el conocimiento, la información y el imaginario de las poblaciones y los turistas del mundo, es esa imagen del Perú cultural, de sus antiguas civilizaciones, del legendario imperio del Tawantinsuyo, a la que se suma crecientemente la idea del Perú como geografía múltiple y diversa.

El medio geográfico en el que se desarrollaron las sociedades y culturas del antiguo Perú tiene características singulares para la vida del hombre. Es, al mismo tiempo, un desafío y una oportunidad. La geografía en el Perú posee múltiples y diversos pisos ecológicos, distribuidos longitudinal y altitudinalmente en forma sucesiva. Esta multiplicidad de medios geográficos se expresa en ocho regiones ecológicas que albergan 84 ecosistemas de los 104 que existen en el mundo, así como 28 climas de los 32 que se registran en el planeta. El territorio peruano es uno de los cinco más ricos del mundo en diversidad biológica. Las investigaciones, aún en curso, han determinado que en su geografía habitan 25000 especies de flora, 315 especies de anfibios, 365 de reptiles, 1760 de aves, 460 de mamíferos y 736 de peces continentales (Rodríguez, 2010). 


\section{La dimensión jurídica de la preservación y protección del patrimonio cultural y natural del Perú}

\section{Las normas internacionales}

A partir de 1982, año en que la Convención del Patrimonio Mundial entró en vigencia para el Perú, la protección de su patrimonio cultural dejó de ser una responsabilidad exclusivamente del Estado nacional y del derecho interno. Desde ese momento, las políticas de protección y las normas legales que regulan la gestión del patrimonio cultural del Perú, pasaron a tener un componente internacional. Este hecho de extremada importancia, no obstante que posee efectos prácticos y legales decisivos para la preservación y conservación del patrimonio cultural y natural del país, es corrientemente soslayado por el poder ejecutivo, el poder legislativo y el poder judicial.

Los poderes del Estado en el Perú aún no asumen de manera sistemática y holística el hecho que la protección y conservación del patrimonio cultural, desde el punto de vista de las políticas públicas y el ordenamiento legal, no se limita a los mecanismos y leyes internas, sino que comprende una instancia internacional de la mayor importancia. Y que esos dos niveles se integran funcionalmente porque las normas de la Convención del Patrimonio Mundial son leyes internas que prevalecen sobre las de origen legislativo, y porque las políticas públicas internacionales aprobadas en el Comité del Patrimonio Mundial son y deben ser el marco de referencia de las políticas públicas nacionales. La ausencia de una visión integrada de las dimensiones nacional e internacional de la protección y preservación del patrimonio cultural, explica hechos como que la ley $\mathrm{N}^{\circ}$ 28296, vigente desde el 22 de julio de 2004, no contenga ninguna referencia a la Convención del Patrimonio Mundial de 1972. El reglamento de la ley 28296, aprobado por DS 011-2006-ED, tampoco hace referencia alguna a la Convención del Patrimonio Mundial.

La protección, gestión y puesta en valor del patrimonio cultural del Perú tiene dos componentes: el nacional y el internacional. Se trata de dos dimensiones normativas y funcionales que forman una estructura integrada de protección. El nacional conformado por las normas legales y las instituciones que regulan las relaciones entre el Estado, los individuos y la sociedad en torno al patrimonio natural y cultural, incluido el inmaterial, y el turismo. Y el internacional integrado por las convenciones culturales de la UNESCO y el derecho internacional consuetudinario de la protección del patrimonio cultural.

Conforme a la Constitución y a las normas generales del derecho internacional, las obligaciones adquiridas por el Perú en las convenciones de la UNESCO son leyes internas. Su ejecución es imperativa y vinculante. Estas normas comprenden los instrumentos internacionales vinculantes que el Perú ha suscrito y ratificado, especialmente la Convención sobre la protección y la promoción de la diversidad de las expresiones culturales (2005), la Convención para la salvaguardia del patrimonio cultural inmaterial (2003), la Convención sobre la protección del patrimonio mundial cultural y natural (1972), la Convención sobre las medidas que deben adoptarse para prohibir e impedir la importación, la exportación y la transferencia de propiedad ilícita de bienes culturales (1970) y la Convención para la protección de los bienes culturales en caso de conflicto armado y reglamento para la aplicación de la Convención (1954). 


\subsection{La incorporación en el derecho interno de las obligaciones asumidas por el Estado en los tratados sobre preservación y protección del patrimonio cultural y natural}

En relación con la incorporación de las normas convencionales al derecho interno, la Constitución asume la teoría monista de un solo ordenamiento jurídico que integra el derecho nacional y el internacional. Así lo establece el artículo 55, cuya redacción reproduce en esencia el artículo 96.1, párrafo primero, de la Constitución española: “Art. 55.- Los tratados celebrados por el Estado y en vigor forman parte del derecho nacional”.

La Constitución española -cuya redacción es seguida por la Constitución peruana en este punto- introduce un requisito formal de derecho interno para la entrada en vigor de los tratados: su publicación en el diario oficial español.

La norma peruana del artículo 55 no establece este requisito. Consiguientemente, los tratados como normas nacionales entran en vigor en nuestro ordenamiento jurídico en la fecha y bajo la formalidad establecida en el texto de cada instrumento. Las obligaciones son exigibles a partir del momento que el tratado es obligatorio para el Estado. En los tratados ejecutivos, al momento de su entrada en vigor. En los instrumentos sujetos a aprobación parlamentaria, al momento de su ratificación por parte del ejecutivo. Los tribunales nacionales están facultados y obligados a aplicarlos a partir de esa fecha y los demás órganos del Estado a acatarlos, así como los individuos legitimados para exigir su respeto y protección en los ámbitos de la justicia constitucional y la vía judicial ordinaria.

\subsection{Las obligaciones contenidas en los tratados internacionales como leyes internas exigibles}

El sistema monista peruano, como el español, no demanda la transformación de las normas de los tratados en leyes internas. Son de ejecución directa, automática. Self-executing. Directamente aplicables. Crean desde su entrada en vigor derechos y obligaciones exigibles por los particulares e invocables ante los tribunales judiciales.

De esta manera, los tratados suscritos por el Perú sobre la protección del patrimonio cultural y natural que se encuentren vigentes son de aplicación directa, automática, continua y permanente. Directa, porque no se requieren actos o formalidades para transformar los tratados en ley interna; automática, porque la entrada en vigor en el derecho interno solo depende de la entrada en vigor del tratado, según sus propias normas y estipulaciones; continua y permanente, porque su vigencia en el tiempo no puede ser afectada por normas del derecho interno y se extiende hasta la vigencia de los propios tratados en conformidad a las estipulaciones que estos prevean al respecto. La Constitución peruana, a diferencia de otros textos constitucionales, ${ }^{1}$ no contiene referencia alguna al derecho internacional general, tampoco a los principios generales del derecho y a la costumbre internacional.

1 En el derecho anglosajón, por ejemplo, existe la regla "International Law is part of the Law of the land", que autoriza a los jueces nacionales a aplicar las reglas imperativas del derecho internacional general. Este principio ha sido recepcionado también por la jurisprudencia de los Estados Unidos. La actual Constitución alemana se va más lejos, pues se establece la primacía del derecho internacional general sobre el derecho interno "[...] las reglas generales del Derecho Internacional Público son parte del Derecho federal. Ellas prevalecen sobre las leyes y producen de forma inmediata derechos y deberes para los habitantes del territorio federado". La Constitución de Italia posee una prescripción análoga al señalar que "[...] el ordenamiento jurídico italiano se ajustará a las normas del Derecho Internacional generalmente reconocido". 
La ausencia de una mención al derecho internacional general en la Constitución parece haber sido una voluntad expresa del legislador. Las únicas normas referidas al ordenamiento jurídico internacional son las contenidas en los artículos 37, 55, 56, 57, 102, 118 de la Constitución y la disposición final cuarta. En todas ellas la remisión al derecho internacional está en relación con "los tratados”, "los tratados en vigor” o "los tratados suscritos y ratificados por el Perú”, no existe en el texto constitucional referencia alguna al derecho internacional general (consuetudinario) o a los principios generales del derecho.

La Constitución remite sus vinculaciones con el ordenamiento jurídico internacional solo al derecho internacional convencional, es decir, al derecho de los tratados vigentes para el país. De esta realidad objetiva del contenido textual de la norma, no puede deducirse, sin embargo, que la Constitución solo reconoce en su ordenamiento jurídico interno la recepción de las normas convencionales del derecho internacional vinculantes para el Estado, excluyendo aquellas que forman parte del derecho internacional general y las obligaciones que se derivan de los principios generales del derecho (ius cogens).

Una interpretación sistemática que vincula la carta constitucional con las obligaciones del Estado peruano derivadas del ordenamiento jurídico internacional, permite llegar a otra conclusión.

El artículo 55 de la Carta Magna adscribe el sistema jurídico peruano a una visión monista en torno a las interrelaciones entre el orden jurídico nacional y el internacional, al establecer sin matices, requisitos o formalidades especiales que las normas de los tratados suscritos por el Estado son parte del derecho interno. Esto significa, como ya se ha visto, que la Constitución recepciona directamente como derecho interno las obligaciones establecidas en los tratados en vigor. De manera complementaria, a través de la Convención de Viena sobre el derecho de los tratados, que es un tratado suscrito y válido para el Perú, se reconoce que "las normas del derecho internacional consuetudinario continuarán rigiendo los asuntos no previstos en las disposiciones de la presente Convención” (Convención de Viena sobre Derechos de los Tratados, 1969).

Más aun, es una regla del derecho internacional general, aceptada por todos los estados que, en ausencia de regulaciones convencionales establecidas en tratados, se aplican en sus relaciones mutuas las normas del derecho consuetudinario. La demanda sobre delimitación marítima que presentó el Estado peruano en la controversia con Chile se funda, precisamente, en ello (Corte Internacional de Justicia - CIJ).

Por otro lado, es legítima la interpretación, al igual que en el caso de la Constitución española, en el sentido que existe en el propio texto constitucional una aceptación implícita de la recepción de las normas del derecho internacional general en el texto de la disposición final cuarta, en la que se prescribe que: "Las normas relativas a los derechos humanos y a las libertades que la Constitución reconoce, se interpretan de conformidad con la Declaración de Derechos Humanos y con los tratados y acuerdos internacionales sobre las mismas materias ratificados por el Perú” (Ministerio de Justicia, 2003).

Como es sabido, la Declaración Universal de los Derechos Humanos no es un tratado y la obligatoriedad de sus normas se deriva por ser parte del derecho internacional consuetudinario. En este punto la Constitución, a través del reconocimiento vinculante de la Declaración, reconoce el internamiento del derecho interno internacional consuetudinario en el ordenamiento jurídico interno. 
De esta manera, a pesar de que no existe en la Constitución una mención expresa en ese sentido, el derecho interno peruano recepciona directamente las normas del derecho internacional convencional y consuetudinario, relativas al patrimonio cultural y natural. En ese sentido, la administración, los jueces y tribunales de la República, en función de cada caso y en razón de la materia que resuelvan, deben aplicar en sus decisiones y resoluciones las normas del derecho internacional de protección y preservación del patrimonio cultural. $^{2}$

\subsection{La primacía de las normas internacionales de protección del patrimonio sobre las leyes internas}

Otro asunto fundamental para la protección legal del patrimonio cultural del Perú en las interrelaciones entre el derecho interno y el derecho internacional, es el relativo al principio de primacía del derecho internacional sobre la ley interna de origen ejecutivo o legislativo.

El principio o postulado de la primacía del derecho internacional establece que las obligaciones asumidas por el Estado en virtud de una norma internacional priman sobre las del derecho interno. Este principio está consagrado tanto por el derecho internacional general como por la Convención de Viena sobre los Tratados de 1969. Al respecto, el T.P.J.I. en el asunto del Intercambio de poblaciones griegas y turcas, estableció que "un Estado que ha contraído válidamente obligaciones internacionales está obligado a introducir en su legislación las modificaciones que sean necesarias para asegurar la ejecución de los compromisos asumidos” (Serie B, nro. 10, p. 20). Complementando lo anterior, la Corte ha explicitado que "el derecho interno no puede prevalecer ni sobre las obligaciones de un Estado conforme al derecho consuetudinario internacional, ni sobre sus obligaciones según el derecho internacional” (Serie A, nro. 9, p. 27).

En el ámbito convencional, el principio ha sido recogido como norma vinculante en el artículo 27 de la Convención de Viena sobre Derecho de los Tratados (1969): “Una parte no podrá invocar las disposiciones de su derecho interno como justificación de su incumplimiento de un tratado. Esta norma se entenderá sin perjuicio de lo dispuesto en el artículo 46”. El artículo 46 de la Convención, a su vez, señala:

un Estado no puede alegar el hecho de que su consentimiento para contraer obligaciones en virtud de un tratado se ha expresado en violación de una disposición de su derecho interno, por lo que se refiere a la competencia para concluir tratados, con objeto de invalidar su consentimiento, a menos que esa violación fuera manifiesta e interesara a una norma de su derecho interno de fundamental importancia. Una violación es manifiesta en el caso de ser objetivamente evidente para cualquier Estado que se rija a sí mismo en esta materia de acuerdo con la práctica normal y de buena fe. (Reurter, 1985, p. 269)

La excepción contenida en el artículo 46.2 hace referencia a una hipótesis de muy difícil aplicación, la existencia de una “violación manifiesta de una norma sustantiva del derecho interno”, pues en la práctica, la hipótesis de la aprobación inconstitucional de un tratado supone la responsabilidad del mismo gobierno que

\footnotetext{
2 Es lo que corresponde aplicar en el caso del hotel Sheraton en la calle Shapi de Cusco, cuya construcción afecta gravemente el valor universal excepcional y las condiciones de integridad y autenticidad del centro histórico como patrimonio de la humanidad.
} 
recurrió al procedimiento inconstitucional, el que, a su vez, es el único responsable de la constitucionalidad del procedimiento.

La contraparte debe suponer de buena fe que el acto de aprobación interna que ha realizado su contraparte se ha efectuado conforme a las disposiciones constitucionales de su derecho interno. Por esta misma razón, es legítimo presumir que el gobierno responsable del acto de aprobación interna no alegará inconstitucionalidad. Esta hipótesis solo debería darse en el caso de verse obligado por la decisión del órgano jurisdiccional responsable del control posterior de la constitucionalidad de los tratados. Pero aun en este extremo, habría que probar que se trata de una violación manifiesta en los términos del inciso 2 del artículo 46 de la Convención. La otra hipótesis es que la alegación venga de un nuevo gobierno. En este caso habrá transcurrido un tiempo y, probablemente, con seguridad se habrá aplicado el tratado, ejecutando sus obligaciones, lo que crearía para al Estado concernido obligaciones ya no derivadas del tratado en sí mismo sino de los actos propios y la aquiescencia.

Tanto en el ámbito del derecho consuetudinario como en el convencional, la alusión al "derecho interno" debe ser precisada. La Corte Internacional ha establecido una jurisprudencia unívoca al respecto: "Un Estado no puede invocar respecto de otro Estado su propia Constitución para sustraerse a las obligaciones que le impone el derecho internacional (consuetudinario) o los tratados en vigor” (T.P.J.I., Serie A/B, nro. 44, p. 24).

De esta manera, el principio de la primacía del derecho internacional (consuetudinario o convencional), recogido en el derecho positivo expresa una regla clara y precisa:

El Estado debe cumplir de buena fe las obligaciones contraídas en virtud de los principios y normas del derecho internacional generalmente reconocido, así como las obligaciones asumidas en virtud de acuerdos internacionales; y, no puede invocar las disposiciones de su derecho interno como justificación de incumplimiento de tales obligaciones. Si este incumplimiento se produce, esto genera la responsabilidad internacional del Estado como autor de un hecho internacionalmente ilícito. (González, Sánchez, \& Sáenz, 1998, p. 258)

El derecho internacional reserva para el derecho interno los procedimientos a través de los cuales el Estado confirma sus obligaciones internacionales y las modalidades de recepción y aplicación de las normas del derecho internacional que lo obligan.

\section{Las normas internas y las políticas de preservación del patrimonio cultural y natural}

Las normas del derecho interno y que deben interpretarse y aplicarse de manera coherente y concordada con los tratados son, esencialmente, los artículos 21 y 195 de la Constitución de la República; el título VIII del código penal «Delitos contra el patrimonio cultural»; la ley general del patrimonio cultural de la Nación, ley 28296; la ley de creación del Ministerio de Cultura, ley 29765; la ley orgánica del poder ejecutivo; la ley de funciones del Ministerio de Cultura; la ley de organización y funciones del Ministerio de Relaciones Exteriores, ley 27357; la ley orgánica de la Policía Nacional del Perú, ley 27238; la ley orgánica de los gobiernos regionales, ley 27867; la ley orgánica de municipalidades, ley 27972; y la ley de los delitos aduaneros, ley 28008. 
En base a las consideraciones anteriores, en todos los asuntos contensiosos los jueces, cortes superiores y la corte suprema, deben aplicar todas y cada una de las normas del derecho internacional convencional y consuetudinario de protección del patrimonio cultural del Perú. La práctica indica, sin embargo, que son casi inexistentes los fallos judiciales que aplican las normas del derecho internacional que obligan al Perú en esta materia. Una realidad similar se observa en el caso de las decisiones administrativas que adoptan las entidades del Estado en relación con la preservación y protección del patrimonio cultural de la nación.

El cuerpo legal que regula la preservación y conservación del patrimonio cultural y natural es uno e integrado y está conformado por las normas de origen legislativo o ejecutivo, propias del derecho interno, y por las leyes que se originan en el derecho internacional a través de los tratados válidos y vigentes sobre la materia.

La Convención del Patrimonio Mundial establece responsabilidades y obligaciones para proteger y conservar el patrimonio cultural y natural exigibles al Estado peruano, a los gobiernos subnacionales y a las poblaciones, así como a los otros estados parte de la Convención y la comunidad internacional.

El Perú, no obstante haber sido el territorio en el que se desarrolló una de las seis civilizaciones más importantes de la humanidad, de su riqueza cultural y natural y de su condición de reino en el pasado colonial, no ha tenido a lo largo de la República de manera constante y sistemática políticas públicas eficaces de protección, preservación y difusión de su patrimonio cultural. La legislación nacional tardía, pues data del siglo XX, se ha referido en el pasado, básicamente, a la condición pública del patrimonio, a las prohibiciones y regulaciones respecto de su posesión y a niveles de protección básicos, como la prohibición de los denuncios mineros en zonas arqueológicas.

Solo a partir de la segunda mitad del siglo XX, a través del Instituto Nacional de Cultura y, más recientemente, con un alcance y cobertura mayor, a partir de la creación del Ministerio de Cultura el año 2010, se cuenta con políticas de protección y promoción del patrimonio orgánicas y técnicamente sustentadas. Sin embargo, aún no existe un sistema nacional de protección, preservación, promoción, difusión y puesta en valor del patrimonio cultural y natural que comprometa al gobierno central, a los gobiernos subnacionales, a las empresas, a las instituciones y a las poblaciones.

\section{El Sistema internacional de preservación y protección del patrimonio cultural y natural de la humanidad (La Convención de 1972)}

La Convención sobre el Patrimonio Cultural de 1972 es el principal instrumento de derecho internacional positivo que regula el régimen jurídico del patrimonio cultural de la humanidad. La Convención, al mismo tiempo, establece un sistema de protección y preservación que se aplica a los bienes culturales, materiales e inmateriales, y a los sitios naturales que forman parte del patrimonio de los Estados y, muy especialmente, en el caso de aquellos que son inscritos en la Lista del patrimonio cultural y natural de la humanidad.

El preámbulo de la Convención define el legítimo interés jurídico de la comunidad internacional en relación con la preservación de los bienes culturales y naturales, asumiendo que un conjunto de instrumentos jurídicos y diplomáticos precedentes (convenciones, recomendaciones y resoluciones internacionales) han consagrado "la importancia que tiene para todos los pueblos del mundo la conservación de esos bienes únicos e irremplazables 
de cualquiera que sea el país al que pertenezcan”. La Convención establece así una responsabilidad de proteger los bienes culturales y naturales de todos los Estados parte. Al mismo tiempo, otorga a determinados bienes, por su significación y valor, la calidad o connotación de constituir un acervo de toda la humanidad, en cuya preservación y protección esta se encuentra comprometida: “Incumbe a la colectividad internacional entera participar en la protección del patrimonio cultural y natural prestando una asistencia colectiva que, sin reemplazar la acción del Estado interesado, la complete eficazmente” (UNESCO, 2016, p. 9).

Aquí, los Estados parte reconocen a la comunidad internacional facultades para concurrir a la preservación y protección de dichos bienes. De manera similar al régimen jurídico internacional de protección de los derechos humanos, la Convención de 1972 establece un régimen de garantía colectiva internacional para preservar el valor universal de los bienes declarados patrimonio de la humanidad.

\section{Las definiciones de patrimonio cultural y patrimonio natural contenidas en la Convención de 1972}

El régimen jurídico internacional de protección requiere una definición jurídica de las nociones de bienes culturales y bienes naturales. Esto lo resuelve la Convención en los artículos 1 y 2, que establecen las siguientes definiciones. Se entiende por patrimonio cultural:

- Los monumentos: obras arquitectónicas, de escultura o de pintura monumentales, elementos o estructuras de carácter arqueológico, inscripciones, cavernas y grupos de elementos, que tengan un valor universal excepcional desde el punto de vista de la historia, el arte o la ciencia.

- Los conjuntos: grupos de construcciones, aisladas o reunidas, cuya arquitectura, unidad e integración en el paisaje, les dé un valor universal excepcional desde el punto de vista de la historia del arte o la ciencia.

- Los lugares: obras del hombre u obras conjuntas del hombre y la naturaleza, así como las zonas, incluidos los lugares arqueológicos que tengan un valor universal excepcional desde el punto de vista histórico, estético, etnológico o antropológico.

En el caso del patrimonio natural, la Convención sigue el mismo criterio de definición del patrimonio cultural, sin utilizar una noción de carácter cualitativo que siempre sería relativa, y opta por una enumeración descriptiva de sitios o lugares. De esta manera, a los efectos de la aplicación de la Convención (noción jurídica), están comprendidos en el concepto de patrimonio natural:

- Los monumentos naturales constituidos por formaciones físicas y biológicas, o por grupos de esas formaciones que tengan un valor universal excepcional desde el punto de vista estético o científico.

- Las formaciones geológicas y fisiográficas y las zonas estrictamente delimitadas que constituyan el hábitat de especies animal y vegetal amenazadas que tengan un valor universal excepcional desde el punto de vista estético o científico.

- Los lugares naturales o las zonas naturales estrictamente delimitadas que tengan un valor universal excepcional desde el punto de vista de la ciencia, de la conservación de la belleza natural. 
Estas definiciones, que son taxativas, como toda norma jurídica, están sujetas a la interpretación que, en el caso del patrimonio cultural, siempre deben responder al principio del deber de protección. Eso significa que en la práctica de la ejecución de las normas de la Convención y del funcionamiento del sistema mundial de protección, el criterio extensivo de interpretación debe aplicarse antes que visiones restrictivas, si ello impacta en un mayor grado y calidad de protección de los bienes de valor universal excepcional cautelados por la Convención.

Bajo este criterio de la interpretación extensiva, existe un proceso dinámico de desarrollo progresivo de las normas de la Convención. Es el caso, por ejemplo, de la decisión adoptada por el Comité del Patrimonio Mundial para proteger de manera independiente a los paisajes culturales como una categoría de bienes del patrimonio cultural bajo tutela del régimen mundial. Taxativamente, los paisajes culturales no están previstos directamente en el artículo 1 de la Convención, pero por aplicación del principio del desarrollo progresivo del derecho internacional, el Comité incorporó a los paisajes culturales como un bien específico del patrimonio cultural, junto a los monumentos, a los conjuntos y los lugares.

\section{El alcance de la noción jurídica del patrimonio cultural y natural de la humanidad}

El derecho internacional general y el derecho consuetudinario han consolidado la noción del patrimonio cultural de la humanidad y la de bienes públicos mundiales. Estos conceptos se han desarrollado en torno al derecho internacional de los derechos humanos, el derecho del mar (los fondos marinos) y aplicado posteriormente al derecho internacional del patrimonio cultural.

A partir de un punto de vista propio de la teoría económica, Inge Kaul, Isabelle Grunberg y Marc A. Stern, han aportado a la concepción de los bienes públicos mundiales definiéndolos como aquellos que no pueden ser aportados exclusivamente por los mercados:

los bienes públicos acarrean beneficios que no pueden ser circunscritos fácilmente a un único 'comprador' (o conjunto de 'compradores') (...) Si bien se comprende que los bienes públicos entrañan efectos externos de gran magnitud (y beneficios difusos), una definición más estricta depende de un juicio acerca de la manera que se consume el bien: si no puede impedirse a nadie que consuma el bien, este es no excluible. Si puede ser consumido por muchos sin agotarse, entonces el bien no tiene rivalidad en el consumo. Los bienes públicos puros, que son raros, tienen ambos atributos. (Kaul, Grunberg, \& Stern, 1999, p. 16)

Desde esta perspectiva, bienes públicos mundiales como la paz o el patrimonio cultural, son bienes públicos puros, es decir, cuyo consumo no tiene límites y a los cuales acceden o deben acceder todas las personas.

El concepto de bien público, desarrollado de manera vinculada a las modernas teorías de la cooperación internacional y del desarrollo, se aplica ciertamente al patrimonio cultural, material e inmaterial. Sin embargo, su conceptualización desde el punto de vista de las responsabilidades asumidas por la comunidad internacional, es más precisa y descriptiva de su objeto, a partir del concepto de patrimonio de la humanidad. Un ejemplo de definición operativa de los bienes públicos globales es el que utiliza la Cooperación Española (2018), que los entiende como: 
Oportunidades y objetivos de los que se beneficia toda la comunidad internacional y cuya gestión supera el ámbito nacional, debiéndose trabajar para alcanzarlos de manera coordinada a nivel global o regional. Son claros ejemplos de BPG los bienes y servicios ambientales proporcionados por la naturaleza, la paz y la seguridad, la estabilidad económica y financiera, la salud global o el conocimiento y la cultura. Todos ellos suponen oportunidades estratégicas que requieren ser abordados mediante un trabajo coordinado más allá de las fronteras de los países.

Si bien el patrimonio cultural y la cultura son bienes públicos globales desde el punto de vista económico y de la cooperación internacional, la conceptualización de estos no puede asimilarse a la noción de patrimonio mundial o patrimonio de la humanidad, que se utilizan como sinónimos. La diferencia estriba en que el concepto de patrimonio implica una relación de posesión o dominio entre los bienes, lugares y elementos culturales con el sujeto que detenta el título; es decir, los Estados y las colectividades locales, las poblaciones. Esta relación de posesión y pertenencia se resuelve jurídicamente a través de las competencias estatales inherentes a la soberanía nacional de los Estados.

La relación Estado-bienes, lugares, elementos y expresiones culturales se da a través del territorio. Los territorios están delimitados por fronteras y estas son los confines de validez de las normas del orden jurídico del Estado. Por esta razón, el territorio es la base material en cuyo interior se ejercen las competencias del Estado sobre un objeto legal determinado. Como señala Clémentine Bories, el territorio cumple la funcionalidad de intermediación entre el Estado y el objeto de sus competencias soberanas, es el punto de anclaje espacial del vínculo establecido por el título de competencia entre un Estado y los objetos jurídicos determinados.

Bories con acierto expresa en ese sentido que, en el caso de la protección del patrimonio cultural, la localización de los significantes culturales en el territorio de un Estado es la fuente del título de competencia del Estado sobre esos significantes (Bories, 2011, p. 76).

Siempre siguiendo a Bories, la competencia del Estado sobre los significantes culturales ubicados en su territorio puede calificarse de real. Y por ello, el título jurídico que disponen los Estados para regular los significantes culturales que se encuentran en su territorio, tiene una naturaleza parcialmente territorial y parcialmente real. De esta manera, en términos generales, se puede señalar que la competencia territorial del Estado sobre los bienes y significantes culturales constituye el título del Estado sobre su patrimonio cultural.

Las competencias estatales y las de las poblaciones, ya que el concepto de patrimonio cultural está siempre vinculado a estas, se refieren a diversos ámbitos territoriales, que pueden ser los del Estado nacional o los de los Estados subnacionales, regionales, provinciales o locales. Como las competencias estriban en el vínculo de la relación Estado-localización territorial del patrimonio cultural, el concepto ha evolucionado a través de las nociones de bienes públicos o patrimonio común de la humanidad, al referir a la comunidad internacional un interés jurídico legítimo para conservar y preservar determinados bienes inestimables de un valor y significado universal. 


\section{El interés jurídico legítimo y la responsabilidad de la comunidad internacional en la protección y preservación del patrimonio cultural y natural de la humanidad}

El sistema internacional de preservación y protección de los bienes culturales y naturales tiene un alcance universal. Las responsabilidades y deberes de protección se refieren a todos los bienes culturales y naturales situados en el territorio de los Estados parte. Estos asumen un conjunto amplio de deberes y obligaciones, principalmente:

a. Identificar y delimitar los diversos bienes situados en su territorio, especialmente aquellos que se han inscrito en la Lista del Patrimonio Mundial.

b. Identificar, proteger, conservar, rehabilitar y transmitir a las generaciones futuras el patrimonio cultural y natural situado en su territorio.

c. Establecer y ejecutar políticas públicas y sistemas de gestión para la preservación y protección, utilizando para ello el máximo de los recursos de que pueda disponer, así como recurrir a la asistencia y cooperación internacional en los ámbitos financiero, artístico, científico y técnico.

De manera complementaria a estas obligaciones básicas, la Convención establece que los Estados parte asumen un deber de hacer. Dirigido a aplicar políticas públicas y sistemas de gestión para una protección y preservación eficaz de su patrimonio cultural y natural, teniendo en cuenta la realidad de cada país. En ese sentido, deben procurar:

a. Adoptar una política general dirigida a atribuir al patrimonio cultural y natural una función en la vida colectiva de sus sociedades y a integrar las políticas de protección de ese patrimonio en sus planes y programas de planeamiento del desarrollo.

b. Establecer o perfeccionar uno o varios servicios de protección, conservación y revalorización del patrimonio cultural y natural, con personal especializado y con los medios financieros y de otra índole que les permitan aplicar de manera eficaz las políticas y estrategias de protección.

c. Llevar a cabo los estudios y la investigación científica y técnica y perfeccionar los métodos de intervención que posibiliten al Estado hacer frente a los peligros que amenacen a su patrimonio cultural y natural.

d. Adoptar las medidas jurídicas, científicas, técnicas, administrativas y financieras más adecuadas para identificar, proteger, conservar, revalorizar y rehabilitar su patrimonio.

e. Facilitar la creación o el desarrollo de las actividades de centros nacionales o regionales de formación en materia de protección, conservación y revalorización del patrimonio cultural y natural, así como promover y estimular la investigación científica con ese fin.

Las directrices operacionales aprobadas por el Comité del Patrimonio Mundial, por primera vez el 2005, precisan aun de manera más específica las obligaciones adquiridas por los Estados en los siguientes términos: 
a. Identificar, proponer inscripciones, proteger, conservar, revalorizar y transmitir a las generaciones futuras el patrimonio cultural y natural situado en su territorio, y prestar ayuda en estas tareas a otros Estados parte que lo soliciten (artículo 46.2 de la Convención del Patrimonio Mundial).

b. Adoptar políticas generales encaminadas a atribuir al patrimonio una función en la vida colectiva (artículo 5 de la Convención del Patrimonio Mundial).

c. Integrar la protección del patrimonio en los programas de planificación general.

d. Establecer servicios de protección, conservación y revalorización del patrimonio.

e. Llevar a cabo estudios científicos y técnicos para determinar medidas adecuadas que contrarresten los peligros que amenacen al patrimonio.

f. Adoptar las medidas jurídicas, científicas, técnicas, administrativas y financieras adecuadas, para proteger el patrimonio.

g. Facilitar la creación o el desarrollo de centros nacionales o regionales de formación en materia de protección, conservación y revalorización del patrimonio y estimular la investigación científica en estos campos.

h. No adoptar deliberadamente medidas que puedan causar daño, directa o indirectamente a su patrimonio o al de otro Estado parte de la Convención (artículo 6.3 de la Convención del Patrimonio Mundial).

i. Presentar al Comité del Patrimonio Mundial un inventario de los bienes aptos para ser incluidos en la Lista del Patrimonio Mundial (la 'lista indicativa'), artículo 11.1 de la Convención del Patrimonio Mundial.

j. Realizar contribuciones periódicas al Fondo del Patrimonio Mundial, por una cuantía que decidirá la Asamblea General de los Estados parte de la Convención (artículo 16.1 de la Convención del Patrimonio Mundial y artículo 5 de las directrices prácticas para la aplicación de la Convención del Patrimonio Mundial).

k. Considerar o favorecer la creación de fundaciones o de asociaciones nacionales públicas y privadas, que tengan por objeto estimular las donaciones a favor de la protección del patrimonio mundial (artículo 17 de la Convención del Patrimonio Mundial).

l. Brindar su apoyo a las campañas internacionales de búsqueda de fondos organizadas en beneficio del Fondo del Patrimonio Mundial (artículo 18 de la Convención del Patrimonio Mundial).

m. Utilizar programas de educación y de información para estimular en sus pueblos el respeto y el aprecio del patrimonio cultural y natural definido en los artículos l y 2 de la Convención del Patrimonio Mundial.

n. Informar ampliamente al público de las amenazas que pesen sobre ese patrimonio.

o. Informar al Comité del Patrimonio Mundial sobre la aplicación de la Convención y sobre el estado de conservación de los bienes. 
Son obligaciones básicas y deberes que los Estados parte de la Convención asumen en relación a su patrimonio cultural y natural. Se trata de obligaciones mínimas que los Estados se comprometen a ejecutar. Más allá de estos componentes esenciales de las políticas públicas de protección y conservación, los Estados en el marco de sus competencias jurisdiccionales pueden adoptar las decisiones y ejecutar las políticas y proyectos para hacer de sus sistemas de gestión del patrimonio estructuras altamente competitivas, rentables y eficaces.

Las políticas nacionales relativas al patrimonio cultural y natural deben, necesariamente, enmarcarse dentro de estas obligaciones y deberes que son asumidos en el ámbito internacional por todo Estado miembro de la Convención.

Más allá del conjunto de estas responsabilidades y deberes en la ejecución de las políticas públicas internas, cada uno de los Estados que forman parte de la Convención de 1972 reconocen el legítimo interés jurídico de la comunidad internacional en su conjunto para coadyuvar en sus esfuerzos nacionales y establecer un sistema de garantías internacionales multilaterales para la preservación, protección y puesta en valor de aquellos bienes culturales y naturales que sean inscritos en la Lista del Patrimonio Mundial de la humanidad, por poseer un valor universal excepcional y cumplir las condiciones mínimas de integridad y autenticidad.

A través del derecho consuetudinario y del derecho convencional, como las disposiciones de la Convención del Patrimonio Mundial de 1972, se ha conferido a la comunidad internacional determinadas competencias con relación al patrimonio cultural en general, y muy particularmente respecto de aquel que tiene un valor excepcional que interesa preservar y transmitir a las futuras generaciones por su valor y significado.

Las competencias de la comunidad internacional sobre el patrimonio cultural, y el patrimonio cultural inestimable tienen tres implicaciones básicas. En primer lugar, la existencia de un interés del conjunto de la comunidad internacional que incluye los ámbitos de las jurisdicciones nacionales internas para proteger, preservar y poner en valor un patrimonio colectivo e intergeneracional. En segundo lugar, la aceptación de un límite al ejercicio de las facultades jurisdiccionales internas en beneficio de una suerte de competencia universal en los deberes de protección y preservación, que es complementaria a la jurisdicción nacional, pero que, en caso de conflicto de facultades, prevalece sobre aquella. En tercer lugar, la interrelación entre el interés común y la aceptación de facultades y obligaciones extranacionales que conlleva a adjudicar a la comunidad internacional una responsabilidad directa e indirecta sobre la protección y preservación de esos bienes.

La existencia de una responsabilidad que atañe al conjunto de la comunidad internacional y no solo a los Estados, implica que los deberes de protección y preservación comprenden también a los pueblos. Y de ahí la pertinencia de atribuir a la humanidad el título de esa responsabilidad compartida de protección. La comunidad internacional, la humanidad, desde el punto de vista jurídico, es la titular de la responsabilidad de proteger y conservar los bienes y elementos culturales que por su significado y alcance comprenden el legítimo interés de los Estados y sus poblaciones, pero que, al mismo tiempo, las exceden ya que la humanidad emerge con un interés jurídico legítimo de protección.

En términos específicos, la responsabilidad colectiva del interés jurídico legítimo de proteger se expresa en los deberes y obligaciones de preservar, de proteger y de no afectar ni dañar. 
Más allá de la consagración de esta responsabilidad y facultades que se atribuyen al conjunto de la humanidad por el derecho consuetudinario, se ha desarrollado un conjunto de normas convencionales que regulan la institución del patrimonio cultural de la humanidad. ${ }^{3}$

En ese sentido, el artículo 6 de la Convención establece que, respetando plenamente la soberanía de los Estados en cuyos territorios se encuentran el patrimonio cultural y natural de valor universal excepcional, y sin perjuicio de los derechos reales previstos por la legislación nacional sobre este patrimonio, los Estados parte reconocen que se trata de un patrimonio universal en cuya protección la comunidad internacional tiene una responsabilidad colectiva y un deber de cooperar.

En base a estas consideraciones contenidas en los dos primeros párrafos del artículo 6 de la Convención, el párrafo 3 de este artículo establece que los estados parte asumen una obligación de no hacer, de no tomar deliberadamente ninguna medida que pueda causar daño, directa o indirectamente, al patrimonio cultural y natural con valor universal excepcional. Esta obligación de no hacer conlleva la obligación de hacer para evitar que los daños al patrimonio continúen produciéndose, adoptando las decisiones de gobierno para eliminar los factores, situaciones o regulaciones legales que afectan o dañan el patrimonio.

La Convención asume que los bienes culturales y naturales de los Estados parte, y aquellos que por su valor universal excepcional comprometen el deber de protección de la comunidad internacional entera, enfrentan peligros y amenazas que pueden significar su deterioro o su destrucción. En función del deber colectivo de proteger y de preservar los bienes frente a esas amenazas, la Convención decide establecer un sistema eficaz de protección colectiva del patrimonio cultural y natural de valor excepcional, organizado de una manera permanente y según métodos científicos y modernos.

\section{El funcionamiento del sistema internacional de protección y preservación del patrimonio de la humanidad}

A partir de estas responsabilidades, obligaciones y deberes de los Estados miembros por una parte, y por otra de la comunidad internacional en su conjunto, la Convención establece un sistema de preservación y protección de los bienes culturales y naturales, integrado por los componentes normativos y funcionales.

\section{Los mecanismos institucionales de protección}

La finalidad y objeto del sistema es la de articular las políticas públicas y los esfuerzos nacionales de preservación y protección en el ámbito nacional, con aquellas promovidas por el sistema internacional de protección, para garantizar la eficacia de las primeras y asegurar intervenciones y recomendaciones decididas en el ámbito multilateral, con el objeto de resolver situaciones de hecho o de derecho (normatividad interna contraria a las disposiciones de la Convención) que amenacen, afecten, deterioren el patrimonio de valor universal

\footnotetext{
Especialmente la Convención del Patrimonio Mundial de 1972, la Convención para la Salvaguardia del Patrimonio Cultural Inmaterial de 2003, las Directrices Prácticas para la aplicación de la Convención del Patrimonio Mundial, las Directrices Operativas para la aplicación de la Convención del Patrimonio Cultural Inmaterial, el Reglamento del Comité Intergubernamental para la protección del Patrimonio Mundial Cultural y Natural y el Reglamento de la Conferencia, Asamblea General de los Estados Partes en la Convención sobre la Protección del Patrimonio Mundial Cultural y Natural.
} 
excepcional o impidan su conservación y puesta en valor, dentro de una concepción sostenible del desarrollo. El eje central del sistema es la inscripción de los bienes y sitios que posean un valor universal excepcional. Y condiciones esenciales de integridad y autenticidad, en la Lista del Patrimonio Mundial y en la Lista del patrimonio en peligro.

El sistema está constituido por los siguientes mecanismos de preservación, protección y gestión:

1. La Lista del patrimonio cultural y natural de la humanidad, o Lista del Patrimonio Mundial.

2. La Lista en peligro de bienes del patrimonio mundial.

3. Las acciones de protección y conservación de los bienes inscritos en las Listas.

4. La asistencia internacional a través del fondo del patrimonio mundial y otras modalidades de cooperación y asistencia financiera.

5. El procedimiento de comunicaciones a través del cual los individuos, las instituciones, las organizaciones no gubernamentales y la sociedad civil hacen llegar denuncias o preocupaciones sobre el estado de conservación de los bienes inscritos en las Listas, con la finalidad de activar los mecanismos de protección.

\subsection{La Lista indicativa}

La Lista indicativa es la primera instancia del mecanismo de protección y preservación de los bienes culturales y naturales a través de su inscripción en la Lista del patrimonio de la humanidad. Consiste en un inventario que elabora el Estado parte con la relación de los bienes culturales, naturales o mixtos que proyecta presentar como propuestas para su inscripción en la Lista del patrimonio de la humanidad. Pero no solamente se trata de una relación de bienes de un valor y un significado extraordinario a nivel nacional. Se trata de bienes respecto de los cuales el Estado reputa la existencia de un valor universal excepcional en los términos definidos por la Convención de 1972. Por esa razón, la inscripción de los bienes en la lista tentativa se orienta de alguna manera por los mismos criterios, definiciones y normas que se aplican para las propuestas de inscripción en la Lista del Patrimonio Mundial. Ello implica que cada bien que se incluye en la Lista tentativa debe tener una fundamentación del valor universal excepcional (VUE), de la presencia de las condiciones de integridad y autenticidad y ser dotados de un sistema de gestión creíble, eficaz y sostenible.

El año 1979, el Comité, en aplicación de lo dispuesto en el artículo 11.1 de la Convención, decidió que los Estados parte elaboren Listas indicativas de los sitios culturales y naturales propuestos para ser inscritos en la Lista del Patrimonio Mundial. Cuatro años después, en la séptima reunión ordinaria del Comité, realizada en Florencia, entre el 07 y el 09 de diciembre de 1983, los Estados parte decidieron dar a esta recomendación una naturaleza compromisoria. Se estableció que todos los Estados debían elaborar su Lista indicativa teniendo como plazo máximo el año 1984. Se decidió, en consecuencia, que con posterioridad a 1984, toda solicitud o nominación de un bien para ser inscrito en la Lista del Patrimonio Mundial cultural o natural no sería examinada por el Comité sin su previo registro en la Lista indicativa. 
De esta manera, se estableció como requisito formal que el registro en la Lista indicativa pasaba a ser un requisito inexcusable para que el Comité pudiese admitir a examen cualquier postulación. Ni ICOMOS, en los casos de bienes culturales, ni la IUCN, en relación con los bienes naturales, estarían en competencia de evaluar la candidatura de un bien sin que este esté previamente inscrito en la Lista indicativa.

Las Listas indicativas no significan, sin embargo, la existencia de un compromiso del Estado para presentar expedientes de inscripción en la Lista del Patrimonio Mundial necesario y obligatoriamente. La presentación o no de un sitio que forma parte de la Lista indicativa sigue siendo una prerrogativa del Estado. Del mismo modo, no prejuzga ni el sentido de la evaluación de los órganos consultivos, ni la decisión del Comité al momento de presentarse un sitio de la Lista indicativa para su evaluación y decisión con miras a ser reconocido como patrimonio mundial. Los órganos consultivos pueden recomendar negativamente la inscripción de un sitio en la Lista indicativa y el Comité evidentemente puede decidir su no inscripción.

¿Cuál es entonces el sentido de la Lista indicativa? Su finalidad es doble. Por un lado, obligar al Estado miembro a hacer una preselección de los sitios que eventualmente puede presentar y avanzar, en cada caso, en la identificación de elementos que puedan configurar un valor universal excepcional. Por otro lado, permite que el Comité, los órganos consultivos y las organizaciones no gubernamentales cuenten con mayores elementos de juicio respecto de los criterios de comparación entre sitios similares y establecer aproximaciones seriadas, que posibiliten metodológicamente un mejor ordenamiento y estudio de las diferentes proposiciones para ser integradas en la Lista del Patrimonio Mundial.

Dentro de esta racionalidad, el Comité ha establecido algunos criterios básicos para la elaboración de las Listas indicativas:

1. Identificar la tipicidad del sitio, es decir, la categoría de bien cultural que se le asigna conforme a las definiciones contenidas en el artículo primero de la Convención (monumentos, conjuntos o lugares, y dentro de estas categorías generales, el tipo específico).

2. Fundamentar los criterios que justifican la propuesta de inscripción.

3. En el caso de los bienes culturales, se puede añadir una referencia al paisaje cultural o al tipo de bien concernido, especialmente cuando se trata de criterios que atañen a la representatividad de bienes seriados.

4. Cuando se trate de bienes culturales seriados, es decir múltiples, se deberá explicitar esa voluntad de inscribir una serie y considerar la posibilidad de registrar solo uno de los bienes seriados o un número limitado o restringido en representación de la serie en su conjunto.

\subsection{La Lista del Patrimonio Mundial}

La Lista del Patrimonio Mundial es una relación de monumentos, conjuntos, lugares, paisajes culturales y sitios naturales que por su valor universal excepcional son inscritos como patrimonio mundial de la humanidad. El Comité ha establecido que esta Lista debe ser representativa, equilibrada y creíble, y responder a cuatro objetivos estratégicos: fortalecer la credibilidad, propiciar una conservación eficaz de los bienes 
inscritos, asegurar la aplicación de medidas eficaces para el fortalecimiento de capacidades en los Estados parte, y fomentar a través de estrategias de comunicación, el conocimiento, la difusión y el apoyo de los pueblos, las instituciones y los gobiernos al patrimonio mundial; reforzando y estimulando el papel de las comunidades locales en la aplicación de la Convención.

\subsubsection{La determinación del valor universal excepcional (VUE)}

Para inscribir un bien o un sitio, el Estado parte debe fundamentar y demostrar con una metodología técnica que posee un valor universal excepcional, en aplicación por lo menos de uno de los siguientes criterios:

(i) Representar una obra maestra del genio creador humano.

(ii) Atestiguar un intercambio de valores humanos considerable, durante un período concreto o en un área cultural del mundo determinada, en los ámbitos de la arquitectura o la tecnología, las artes monumentales, la planificación urbana o la creación de paisajes.

(iii) Aportar un testimonio único, o al menos excepcional, sobre una tradición cultural o una civilización viva o desaparecida.

(iv) Ser un ejemplo eminentemente representativo de un tipo de construcción o de conjunto arquitectónico o tecnológico, o de paisaje que ilustre uno o varios períodos significativos de la historia humana.

(v) Ser un ejemplo destacado de formas tradicionales de asentamiento humano o de utilización de la tierra o del mar, representativas de una cultura (o de varias culturas), o de interacción del hombre con el medio, sobre todo cuando este se ha vuelto vulnerable debido al impacto provocado por cambios irreversibles.

(vi) Estar directa o materialmente asociado con acontecimientos o tradiciones vivas, ideas, creencias u obras artísticas y literarias que tengan una importancia universal excepcional. (El Comité considera que este criterio debería utilizarse preferentemente de modo conjunto con los otros criterios).

(vii) Representar fenómenos naturales o áreas de belleza natural e importancia estética excepcionales.

(viii) Ser ejemplos eminentemente representativos de las grandes fases de la historia de la tierra, incluido el testimonio de la vida, de procesos geológicos en curso en la evolución de las formas terrestres o de elementos geomórficos o fisiográficos significativos.

(ix) Ser ejemplos eminentemente representativos de procesos ecológicos y biológicos en curso en la evolución y el desarrollo de los ecosistemas terrestres, acuáticos, costeros y marinos y las comunidades de vegetales y animales terrestres, acuáticos, costeros y marinos.

(x) Contener los hábitats naturales más representativos y más importantes para la conservación in situ de la diversidad biológica, comprendidos aquellos en los que sobreviven especies amenazadas que tienen un valor universal excepcional, desde el punto de vista de la ciencia o de la conservación. 


\subsubsection{La condición de autenticidad}

De manera complementaria, el Estado parte debe fundamentar en la presentación del expediente, cuando se trata de bienes comprendidos en los criterios (i) - (vi), las condiciones de autenticidad de estos bienes.

La fundamentación de la presencia de las condiciones básicas de autenticidad está regulada por las directrices prácticas de la Convención de 1972. Es muy importante tener en cuenta que cada cultura posee una especificidad no solamente histórica, sino en la visión del mundo que la sustenta y en los elementos materiales utilizados en la construcción del bien, así como en torno a la presencia de elementos inmateriales concomitantes.

En ese sentido, las directrices operativas establecen que la propuesta de inscripción debe fundamentar de forma fehaciente y creíble que la autenticidad se sustenta en atributos como la forma y el diseño, los materiales y la sustancia, el uso y la función, las tradiciones, técnicas y sistemas de gestión, la localización del entorno, la lengua y otras formas de patrimonio inmaterial, la espiritualidad y sensibilidad asociadas al bien, entre otros factores.

Las directrices operativas establecen que la utilización de estos criterios o fuentes permite una valoración de las dimensiones artísticas, históricas, sociales y científicas específicas de cada patrimonio cultural.

En ese contexto, el Estado parte debe identificar en el expediente los atributos que sustentan la autenticidad.

La condición de autenticidad, en principio, excluye la reconstrucción de restos arqueológicos, edificios o barrios históricos. La regla general es que la reconstrucción es una expresión física incompatible con el criterio de autenticidad. Salvo circunstancias muy excepcionales que deben justificarse de una manera científica y con una documentación completa y detallada. La reconstrucción sustentada en conjeturas o en criterios subjetivos es incompatible con la condición de autenticidad mínima que debe complementar la demostración de la existencia del valor universal excepcional del bien.

\subsubsection{La condición de integridad}

La condición de integridad es un requisito esencial para que un bien pueda ser inscrito en la Lista del Patrimonio Mundial. Las directrices prácticas -que son criterios de interpretación y aplicación de las disposiciones de la Convención- establecen que la integridad mensura el carácter integrado intacto del patrimonio cultural y/o natural y de sus atributos. Establecen de manera precisa los elementos que sustentan la integridad y cuya existencia en un bien debe corresponder a una medida que justifique la existencia de esta condición. 
Tres son los criterios respecto de los cuales se debe sustentar la medida de la integridad: (a) el bien debe, en consecuencia, poseer todos los elementos necesarios para expresar su valor universal excepcional; (b) tener un tamaño adecuado que permita la representación completa de las características y los procesos que transmiten la importancia del bien; y (c) referenciar los efectos adversos que el desarrollo y/o las negligencias han afectado o incidido en la conservación del bien.

El párrafo 89 de las directrices prácticas establece:

En el caso de los bienes propuestos para inscripción según los criterios (i) - (vi), el material físico del bien y/o sus características significativas deben encontrarse en buen estado y el impacto de los procesos de deterioro debe estar controlado. Debe incluirse una proporción importante de los elementos necesarios para transmitir la totalidad del valor que representa el bien. También se mantendrán las relaciones y las funciones dinámicas presentes en los paisajes culturales, las ciudades históricas o en otros bienes históricos vivos, esenciales para mantener su carácter distintivo.

Una previsión similar se establece para los bienes propuestos para inscripción según los criterios (vii) - (x), en cuyo caso:

los procesos biofísicos y las características de la tierra deberán estar relativamente intactos. No obstante, se reconoce que ninguna zona está totalmente intacta y que todas las zonas naturales se encuentran en un estado dinámico que, en cierta medida, entraña contactos con seres humanos. Las actividades de estos, comprendidas las de las sociedades tradicionales y las comunidades locales, se desarrollan a menudo en zonas naturales. Estas actividades pueden estar en armonía con el Valor Universal Excepcional del área y ser sostenibles desde un punto de vista ecológico.(UNESCO, 2008, p. 26, párr. 90)

\subsection{El seguimiento y monitoreo de la protección y conservación de los bienes inscritos en las Listas}

El sistema, una vez inscrito un bien en la Lista, posee diversos procedimientos de seguimiento, evaluación, supervisión y monitoreo de la gestión del bien con miras a asegurar su preservación, protección y puesta en valor sostenible. Estos mecanismos son cinco:

a. Los informes periódicos

Al formar parte de la Convención, los Estados parte adquieren la obligación (artículo 29) de presentar informes periódicos al Comité sobre el estado de conservación del bien, la estructura y eficacia de su sistema de gestión, la existencia de amenazas al VUE del bien y las decisiones adoptadas en torno a la aplicación de la Convención, las directrices operativas y las decisiones del Comité. Esta obligación no solo es del Estado central, atañe también a los gobiernos subnacionales, regionales y locales en cuyas jurisdicciones se encuentra el bien. El objetivo de los informes periódicos es que el Comité cuente con la información detallada del estado de conservación del bien y las amenazas y problemas que puedan enfrentar. El Comité hace una evaluación de cada caso y adopta las decisiones y recomendaciones más adecuadas para preservar el bien y realizar los cambios que sean necesarios en las políticas de preservación del bien. 
Conforme a lo establecido en el párrafo 201 de las directrices prácticas, los objetivos principales del procedimiento de presentación de informes periódicos son:

i. Proporcionar una evaluación de la aplicación de la Convención por el Estado parte.

ii. Determinar si el Valor Universal Excepcional de los bienes inscritos en la Lista se mantiene o si sufre amenazas o deterioro.

iii. Proporcionar información y datos actualizados sobre el bien, con la finalidad de registrar cambios en sus condiciones y estado de conservación.

iv. Propiciar un mecanismo de cooperación regional de intercambio de información y experiencias entre los Estados.

Con esta última finalidad, la de promocionar y estimular las prácticas regionales de conservación, la presentación de los informes ha adquirido una modalidad regional. Los informes son una fuente indispensable y valiosa para el monitoreo permanente que realiza el Comité.

Los informes periódicos se realizan en un ciclo de seis años. Cada Estado parte presenta su informe periódico a más tardar el 15 de diciembre del sexto año siguiente al último informe. Son presentados por los Estados parte al Comité a través del Centro del Patrimonio Mundial. El Comité a su vez hace un informe que se presenta a la Conferencia General de UNESCO.

\section{b. Las misiones de cooperación}

Las misiones de cooperación constituyen un mecanismo destinado a reforzar las capacidades para la gestión y preservación de un bien inscrito en la Lista. Normalmente, están conformadas por personal técnico, altamente especializado, del Centro del Patrimonio Mundial y de los órganos consultivos. Su financiamiento corre a cargo del Estado parte y en algunos casos -excepcionales, por cierto- a través del Fondo del Patrimonio Mundial. Su objeto y fines son variados, pero en todos los casos se enmarcan en las políticas de preservación y protección, siempre dentro del marco normativo de la Convención y las orientaciones de las directrices prácticas. Puede ser desde misiones que colaboren con el Estado parte en la elaboración de su Lista indicativa, hasta aquellas dirigidas a ejecutar las recomendaciones del Comité, realizar estudios técnicos o análisis normativos o evaluaciones in situ. En muchos casos tienen un muy positivo efecto preventivo. Es el caso de misiones dirigidas a evaluar si determinadas intervenciones de los gobiernos centrales o subnacionales en el bien o en su área de influencia pueden o no tener efectos nocivos en la preservación del VUE o las condiciones de autenticidad o integridad. Estas misiones tienen en esa perspectiva un enorme sentido positivo y constructivo en las políticas de preservación y protección. Pues pueden conllevar la suspensión o cancelación de ciertas obras o políticas potencialmente destructivas del patrimonio. Los resultados de las misiones de cooperación se expresan en un informe que es presentado al Estado miembro y al Comité del Patrimonio Mundial. 
En los últimos años, el Perú ha solicitado y llevado a cabo misiones de cooperación preventivas para analizar las situaciones de vulnerabilidad del Santuario de Machu Picchu, la Ciudad del Cusco y el Centro histórico de Lima.

\section{c. El monitoreo reactivo}

Este mecanismo no depende exclusivamente de la voluntad del Estado parte. Ciertamente, se puede activar a solicitud de este. Pero también, y es lo más usual, a través de una decisión autónoma del Comité del Patrimonio Mundial. Se activa cuando el Comité, a través de las evaluaciones del Centro del Patrimonio Mundial y los órganos consultivos, constata la existencia de una situación seria de vulnerabilidad del bien. Es decir, la existencia de peligros reales potenciales que pueden afectar o deteriorar el VUE del bien, o afectar sus condiciones de integridad y autenticidad.

Su aplicación comprende usualmente las siguientes fases: constatados los peligros o amenazas, el Comité solicita al Estado miembro un informe detallado que debe presentar a más tardar el 1 de febrero del año siguiente. Si el Comité juzga que es necesaria una evaluación en el terreno, se decide el envío de la Misión de Monitoreo Reactivo, que es conformada por representantes del Centro del Patrimonio Mundial y de los organismos consultivos. Según se trate de un bien cultural, natural o mixto, los expertos provendrán de ICOMOS, la IUCN o ICCROM. A la Misión se integran representantes del Estado parte y de las entidades gestoras del bien. Pero la elaboración del informe es responsabilidad autónoma e independiente del Centro del Patrimonio Mundial y los organismos consultivos. Este informe debe contener un análisis técnico-científico de los elementos que afectan al bien y de las características del sistema de gestión. Necesariamente contiene conclusiones y recomendaciones dirigidas a eliminar las amenazas o peligros reales, la adopción de acciones urgentes y de mediano y largo plazo, incluidas recomendaciones de naturaleza normativa, si fuesen necesarias. El sentido del informe es recuperarlos, restituirlos, protegerlos o mejorarlos. El informe se somete a consideración del Comité. El Estado Parte, por cierto, presenta sus propias evaluaciones y observaciones.

El Comité analiza el informe y las apreciaciones del Estado parte, las valora desde la perspectiva de la conservación del VUE del bien y adopta una decisión, que puede orientarse en diverso sentido: determinar que el bien no está amenazado, y si constata que lo está, decidir la adopción de las medidas y acciones que el Estado miembro debe ejecutar para evitar el deterioro de la situación y/o recuperar los valores del bien. En caso extremo de afectación del VUE y de serias limitaciones del sistema de gestión del bien, el Comité puede decidir que la única alternativa para actuar positivamente en su estado de conservación es incluyendo el bien en la Lista en peligro.

\section{d. El mecanismo de seguimiento reforzado}

Con la finalidad de asegurar el cumplimiento de las recomendaciones en relación a los bienes que en su evaluación requieren medidas y acciones urgentes para su preservación, y dada la comprobación de la existencia de dificultades por parte de los Estados para adoptar las medidas correctivas y preventivas recomendadas para la conservación del VUE, el Comité en su 31 período de sesiones (Christchurch, 2007), adoptó este 
procedimiento de monitoreo, a fin de garantizar a través de una acción conjunta entre el Estado parte y el Comité, representado por el Centro y los órganos consultivos, la adecuada y eficaz aplicación de sus decisiones. Se trata de un monitoreo constante y bajo seguimiento permanente. Entre los bienes que han sido sometidos al seguimiento reforzado se encuentran el Parque Nacional Virunga y el Parque Nacional Garamba, en la República Democrática del Congo, los Monumentos Medievales de Kosovo en Serbia, el Templo de Preah Vihea en Camboya y el Santuario de Machu Picchu.

El mecanismo de seguimiento reforzado implica, también, el envío de misiones al terreno, la elaboración de un informe con conclusiones y recomendaciones y las decisiones del Comité que dado el caso -persistencia de las amenazas graves al VUE del bien-, pueden implicar su inscripción en la Lista en peligro.

\section{e. La Lista en peligro}

El artículo 11.4 de la Convención instituye la Lista en peligro como un recurso extremo de protección y preservación del valor universal excepcional de los bienes inscritos en la Lista del Patrimonio Mundial. Aquellos bienes cuyo sistema de gestión nacional se muestra insuficiente y sin capacidad para gestionar adecuadamente un bien, cuyo VUE se encuentra en peligro por factores que lo afectan gravemente o que lo pueden deteriorar o eliminar de manera inminente, son inscritos en la Lista en peligro. Actualmente forman parte de ella 54 sitios. Entre ellos, algunos icónicos como el Centro Histórico de Viena, Abu Mena en Egipto, la Ciudad Arqueológica de Samara en Irak, la Ciudad Vieja y las Murallas de Jerusalén, y la Zona Arqueológica de Chan Chan en el Perú.

El sistema de protección internacional de tutela y protección del patrimonio cultural tiene un sentido teleológico, que orienta el funcionamiento del sistema en su conjunto y de cada uno de sus mecanismos. El significado de la Lista en peligro es asegurar la protección y conservación del bien a través de la acción de la comunidad internacional, que ejerce su deber de garantía para preservar el VUE de los bienes incluidos en la Lista. No se trata de una 'penalización' del Estado en cuyo territorio está inscrito el bien, sino de una medida extrema para preservar los valores del sitio.

Una vez inscrito el bien en la Lista en peligro, se movilizan recursos técnicos y financieros, así como una presión constructiva desde el punto de vista político, para que el Estado concernido, las entidades encargadas de la gestión, las asociaciones y entidades interesadas, las colectividades locales y las poblaciones asuman sus responsabilidades para dotar al sitio de un plan y un sistema de gestión encaminado a eliminar los factores de daño y dar sostenibilidad al valor universal excepcional del bien.

Si los planes de emergencia y las medidas de urgencia dan resultados y se eliminan las causas del deterioro del VUE o sus potenciales amenazas, el bien puede salir de la Lista en peligro, siempre y cuando haya sostenibilidad en los cambios en el sistema de gestión. Esta decisión solo la puede tomar el Comité conforme a sus reglas de procedimiento y teniendo en cuenta las recomendaciones técnico-científicas del Centro del Patrimonio Mundial y los órganos consultivos. En la hipótesis extrema opuesta, si no se logra mejorar la situación del bien y el valor universal excepcional por grave deterioro pierde vigencia, el Comité puede tomar la decisión de excluir el bien definitivamente de la Lista del Patrimonio Mundial. 
El sentido de la Lista en peligro, es acceder a un nivel de protección monitoreado por el Comité, por la insuficiencia de los sistemas de gestión en la esfera nacional. En la práctica, la opinión pública, los gobiernos y los decisions makers de la gestión del bien, asumen la posibilidad o su inclusión como un deshonor o una onerosa expresión del fracaso del sistema de gestión a nivel nacional. En esa medida, incluir un bien en la Lista en peligro evidentemente afecta la credibilidad de un gobierno nacional o local, o de ambos. Es malo para la imagen gubernamental, pero muy positivo para el bien, que accede a un nivel de protección superior.

\subsection{La asistencia internacional a través del Fondo del Patrimonio Mundial y otras modalidades de cooperación y asistencia financiera}

La Convención creó el Fondo del Patrimonio Mundial como el mecanismo financiero del sistema. Sus recursos provienen de dos fuentes: contribuciones obligatorias de los Estados miembros y los aportes voluntarios de los mismos Estados parte y de otros agentes.

Se trata de un mecanismo de asistencia financiera internacional que siempre se entiende como complementario a los aportes nacionales y cuyas actividades deben privilegiar los aportes a los países con mayor insuficiencia de recursos. El Comité ha establecido un orden prioritario de asistencias, en función de la naturaleza del financiamiento, las mismas que siempre se ejecutan a solicitud de parte:

1. Asistencia financiera de urgencia.

2. Asistencia para la gestión y conservación de los bienes inscritos en la Lista. Esta puede no ser necesariamente financiera, pues puede comprender la cooperación técnica, y las actividades promocionales y educativas.

3. La asistencia preparatoria.

Esas tres modalidades se aplican en función de una prioridad declarada: los bienes que se encuentran en la Lista en peligro. Dentro de la aplicación de esta prioridad, en función del Estado requiriente, los fondos se canalizan atendiendo de manera preferente los siguientes casos:

- Demanda de un país menos avanzado o de ingresos bajos en la tipología establecida por el Comité de políticas de desarrollo del ECOSOC.

- Solicitudes de países de ingresos medios bajos, conforme a los criterios definidos por el Banco Mundial.

- Demandas de los pequeños países insulares.

- Cualquier Estado parte que enfrenta una situación de postconflicto armado.

Las directrices operativas y la práctica en la ejecución de los recursos del Fondo, establecen, asimismo, una política de equilibrio entre los financiamientos de conservación del patrimonio cultural y natural y los destinados a mejorar la gestión y apoyar la asistencia preparatoria. Todas las solicitudes de asistencia superior a 5000 dólares deben ser objeto de una evaluación y las recomendaciones correspondientes de los órganos consultivos, en función de su especialidad. 


\subsection{El procedimiento de comunicaciones a través del cual los individuos, las instituciones, las organizaciones no gubernamentales y la sociedad civil hacen llegar denuncias o preocupaciones sobre el estado de conservación de los bienes inscritos en las Listas, con la finalidad de activar los mecanismos de protección}

Este procedimiento se ha ido afirmando y consolidando en la práctica. Tiene su base en las disposiciones de la Convención que atribuyen a toda la comunidad internacional responsabilidades en la protección y preservación del patrimonio cultural y natural. Este deber de participación en su enunciado general ha dado lugar a un verdadero sistema de peticiones de entidades de la sociedad civil y personas individuales que hacen llegar al Comité, a través del Centro, información que puede indicar situaciones que afectan, deterioran o amenazan los valores de un bien.

El mecanismo es similar, aunque menos formal que el de una denuncia o peticiones en el caso de los derechos humanos. Los individuos o las asociaciones hacen llegar cartas o comunicaciones al Comité, expresando su preocupación o transmitiendo información respecto de hechos, políticas o situaciones que afectan o pueden afectar el valor universal excepcional de un bien.

El Centro del Patrimonio Mundial recibe, clasifica, registra y procesa estas comunicaciones y, allí donde el caso amerita, las transmite al gobierno concernido para que se informe sobre el particular. Los gobiernos absuelven estas comunicaciones y el Centro y los órganos consultivos hacen una valoración y establecen recomendaciones. Cuando las comunicaciones aisladas conforman una situación, los órganos consultivos las pueden incorporar a sus informes sobre la gestión del bien y efectuar las recomendaciones pertinentes al Estado parte.

\section{La preservación y protección de los bienes culturales y naturales del Perú inscritos en la Lista del Patrimonio Mundial}

El Perú ratificó la Convención del Patrimonio Mundial tardíamente, el 21 de diciembre de 1981. Entró en vigencia el 24 de mayo de 1982, diez años después de su adopción. Y lo hizo a partir de la decisión de inscribir en la Lista al Santuario Histórico de Machu Picchu y la Ciudad del Cusco. Antecedieron al Perú como miembros del sistema, Ecuador (1975), Bolivia (1976), Brasil (1977), Argentina (1978) y Chile (1980).

A partir de ese momento, el Perú devino en Estado parte de la Convención y asumió todos los deberes y obligaciones que se derivan de esa membrecía. Esto significó que las políticas públicas y las conductas del Estado, las instituciones, las empresas y la población dejaron de estar reguladas solamente por el derecho interno, pasando a ser normadas también por el derecho internacional. El Estado peruano con esta decisión elevó los estándares de protección del patrimonio cultural y natural. 


\section{Los bienes peruanos inscritos en la Lista del patrimonio cultural y natural de la humanidad}

Desde esa fecha el Perú ha inscrito doce bienes y sitios culturales en la Lista del Patrimonio Mundial. Ocho en la Lista del patrimonio cultural, dos en la del patrimonio natural, y dos como patrimonio mixto. La siguiente es la relación de sitios inscritos en orden cronológico.

1. Ciudad del Cusco, patrimonio cultural (1983)

2. Santuario Histórico de Machu Picchu, patrimonio mixto (1983)

3. Parque Nacional de Huascarán, patrimonio natural (1985)

4. Sitio Arqueológico de Chavín, patrimonio cultural (1985)

5. Zona Arqueológica de Chan Chan, patrimonio cultural - Lista en peligro (1986)

6. Parque Nacional de Manu, patrimonio natural (1987)

7. Centro Histórico de Lima, patrimonio cultural (1988-1991)

8. Parque Nacional del río Abiseo, patrimonio mixto (1990-1992)

9. Líneas y Geoglifos de Nazca y Palpa, patrimonio cultural (1994)

10. Centro Histórico de la Ciudad de Arequipa, patrimonio cultural (2000)

11. Ciudad Sagrada de Caral - Supe, patrimonio cultural (2009)

12. Qhapaq Ñan - sistema vial andino, patrimonio cultural (2014)

La fundamentación del VUE de los bienes y sitios inscritos por el Perú en la Lista del Patrimonio Mundial (incluyendo las declaraciones retrospectivas de los bienes inscritos antes del 2005) se ha realizado teniendo en cuenta los siguientes criterios establecidos en la Convención de 1972.

El criterio (i), que reconoce al bien un valor universal excepcional por representar una obra maestra del genio creador humano. Ha sido acreditado por el Comité del Patrimonio Mundial en los casos del Santuario Histórico de Machu Picchu, la Ciudad del Cusco, la Zona Arqueológica de Chan Chan, las Líneas y Geoglifos de Nazca, el Centro Histórico de Arequipa, la Ciudad Sagrada de Caral y el Qhapaq Ñan - sistema vial andino.

El criterio (ii) acredita el VUE de un bien cuando se constata que es testimonio de un intercambio de valores humanos considerable, durante un período concreto o en un área cultural del mundo determinada, en ámbitos de la arquitectura o la tecnología, las artes monumentales, la planificación urbana o la creación de paisajes. Ha sido aplicado por el Comité en el caso de la inscripción del Quapaq Ñan.

El criterio (iii), referido a bienes que aportan un testimonio único, o al menos excepcional, sobre una tradición cultural o una civilización viva o desaparecida. Ha sido utilizado por el Comité para demostrar el VUE del Santuario Histórico de Machu Picchu, la Ciudad del Cusco, el Sitio Arqueológico de Chavín, la Zona Arqueológica de Chan Chan, el Parque Nacional de Río Abiseo, las Líneas y Geoglifos de Nazca, la Ciudad Sagrada de Caral y el Quapaq Ñan. 
El criterio (iv) establece que un bien puede acreditar su valor universal excepcional si constituye un ejemplo eminentemente representativo de un tipo de construcción o de conjunto arquitectónico, o tecnológico, o de paisaje, que ilustre uno o varios períodos significativos de la historia humana. Ha sido aplicado al reconocimiento de valor universal excepcional de la Ciudad del Cusco, el Centro Histórico de Lima, las Líneas y Geoglifos de Nazca, el Centro Histórico de Arequipa, la Ciudad Sagrada de Caral, y el Quapq Ñan.

El valor universal excepcional reconocido a sitios naturales por representar fenómenos naturales o áreas de belleza natural e importancia estética excepcionales, criterio (vii); ser ejemplos eminentemente representativos de las grandes fases de la historia de la tierra, incluido el testimonio de la vida, de procesos geológicos en curso de la evolución de las formas terrestres o de elementos geomórficos o fisiográficos significativos, criterio (viii); han sido aplicados para fundamentar el VUE del Parque Nacional del Huascarán (ambos criterios), del Santuario Histórico de Machu Picchu y del Parque Nacional de Río Abiseo (solo el criterio vii).

Siempre desde la perspectiva del reconocimiento del valor inestimable de bienes naturales, el criterio (ix), referido a lugares que son ejemplos eminentemente representativos de procesos ecológicos y biológicos en curso, en la evolución y desarrollo de los ecosistemas terrestres, acuáticos, costeros y marinos, y las comunidades de vegetales y animales terrestres, acuáticos, costeros y marinos, ha servido para fundamentar el valor universal excepcional del componente natural del Santuario Histórico de Machu Picchu, y los parques nacionales de Manu y Río Abiseo.

Finalmente, también en los casos de los parques nacionales de Manu y Río Abiseo ha sido aplicado el criterio (x), que atribuye el VUE si se constata que los sitios contienen los hábitats naturales más representativos y más importantes para la conservación in situ de la diversidad biológica, comprendidos aquellos en los que sobreviven especies amenazadas que tienen un valor universal excepcional desde el punto de vista de la ciencia o de la conservación.

El hecho que el Perú haya inscrito entre los años 1983 y 2014 doce bienes en la Lista del Patrimonio Mundial denota una activa política cultural interna y externa de protección y promoción del patrimonio cultural del país. Los primeros sitios que inscribió el Perú entre 1983 y 1992 se hicieron en un período en el que las directrices prácticas sobre la aplicación de la Convención de 1972 aún no se habían desarrollado suficientemente. No se habían establecido criterios científicos y técnicos específicos para la definición del valor universal excepcional y las condiciones de autenticidad e integridad, y tampoco el Comité del Patrimonio Mundial había definido los atributos esenciales que los sistemas de gestión para la protección y preservación deben obligatoriamente cumplir.

El sistema internacional de protección en ese período era más laxo y la apreciación del valor universal excepcional de los bienes presentados por los Estados miembros para considerar su inscripción en la Lista obedecía a una pluralidad de apreciaciones cualitativas, sin métodos unificados de valoración. Los bienes inscritos hasta el año 2005, no eran objeto de una declaración de valor universal excepcional. Recién con la aprobación de las directrices prácticas en el año 2005, el sistema estableció la obligatoriedad de que todo bien inscrito debía poseer una declaración de valor universal excepcional. Esta práctica positiva se empezó a aplicar a partir del año 2007. 
Tabla 1

Patrimonio Mundial del Perú: criterios utilizados para la fundamentación del VUE de los bienes y sitios peruanos inscritos en la lista del Patrimonio Mundial de la Humanidad

\begin{tabular}{|c|c|c|c|c|c|c|c|c|c|}
\hline BIEN / SITIO & & & & & RIOS & & & & \\
\hline Santuario Histórico de Machu Picchu & (i) & & (iii) & & & (vii) & & (ix) & \\
\hline Ciudad del Cusco & & & (iii) & (iv) & & & & & \\
\hline Parque Nacional de Huascarán & & & & & & (vii) & (viii) & & \\
\hline Sitio Arqueológico de Chavín & & & (iii) & & & & & & \\
\hline Parque Nacional de Manu & & & & & & & & (ix) & $(x)$ \\
\hline Centro Histórico de Lima & & & & (iv) & & & & & \\
\hline Parque Nacional de Río Abiseo & & & (iii) & & & (vii) & & (ix) & $(x)$ \\
\hline Líneas y Geoglifos de Nazca & (i) & & (iii) & (iv) & & & & & \\
\hline Centro Histórico de la ciudad de Arequipa & (i) & & & (iv) & & & & & \\
\hline Ciudad Sagrada de Caral & (i) & & (iii) & (iv) & & & & & \\
\hline Qhapaq Ñan - sistema vial andino & & (ii) & (iii) & (iv) & (vi) & & & & \\
\hline
\end{tabular}

Por esta razón, las nominaciones peruanas relativas a la Ciudad Sagrada de Caral - Supe, y muy especialmente la del Qhapaq Ñan - sistema vial andino, demandaron expedientes sumamente técnicos, con metodologías predeterminadas y exigencias normativas que implicaron labores de investigación y de sustentación del valor universal excepcional a través de un trabajo de campo riguroso y la investigación histórica, arqueológica, geográfica, arquitectónica y etnohistórica, siempre en función de los elementos de método contenidos en las directrices prácticas y aquellos derivados de la experiencia acumulada de los órganos consultivos del sistema y del Centro del Patrimonio Mundial. El caso del Qhapaq Ñan es paradigmático en la historia del patrimonio mundial, pues se trató de la primera nominación seriada de naturaleza transnacional.

El punto de referencia esencial de la protección de los sistemas de gestión nacional y del monitoreo internacional de los sitios del Perú inscritos en la Lista del Patrimonio Mundial, es la declaración del valor universal excepcional y los parámetros de sus respectivas condiciones de integridad y autenticidad. La declaración del valor universal excepcional no solo tiene el valor de sustentar el interés de la humanidad en relación a la preservación y protección del valor universal excepcional y a las características y atributos de significación universal. Tiene, asimismo, implicancias prácticas específicas. Los sistemas de gestión, las intervenciones del Estado nacional o de los gobiernos subnacionales (regionales o municipales) deben imperativamente concebirse en términos de no afectar el valor universal excepcional ni deteriorarlo. Lo mismo en relación a la integridad y autenticidad. El valor universal excepcional constituye el límite de la acción del Estado y del impacto del turismo en la protección y conservación del bien. Por ello, los sistemas de gestión de administración de cada uno de los sitios que el Perú tiene inscritos en la Lista del Patrimonio Mundial deben estar obligatoriamente concebidos y ejecutados en términos de no 
afectar y, por el contrario, proteger y preservar los atributos del valor universal excepcional y los elementos constitutivos de las condiciones de autenticidad e integridad. Esta es una exigencia esencial en torno a la puesta en valor económico del bien a través del turismo. En el Perú, como ya se ha indicado, casi el 100\% del turismo interno y externo se realiza en torno al patrimonio cultural, y dentro de este, en bienes culturales o naturales que están inscritos en la Lista.

Esta realidad exige que las políticas públicas y la actividad privada en torno al turismo, es decir, las actuaciones e intervenciones del Estado, las empresas privadas, los ciudadanos y los turistas, estén reguladas para no afectar el valor universal excepcional. Esto requiere una concepción y una visión del turismo sostenible.

En ese contexto, con la finalidad de dotar a todos los bienes inscritos en la Lista del Patrimonio Mundial de una declaratoria de valor universal excepcional, el Comité del Patrimonio Mundial a partir del 2007 decidió que los estados miembros inicien un proceso para elaborar proyectos de declaración de valor universal excepcional de los bienes inscritos con anterioridad al 2007, con el objeto de someter esos proyectos a la consideración y evaluación del Comité para su aprobación.

Estas declaraciones retrospectivas se vienen realizando a partir de la definición del valor universal excepcional que se encuentra en las directrices prácticas, la misma que establece que el «valor universal excepcional significa una importancia cultural y/o natural tan extraordinaria que trasciende las fronteras nacionales y cobra importancia para las generaciones presentes y venideras de toda la humanidad. El concepto del valor universal excepcional no es estático. Conforme a la práctica de preservación y protección de Comité evoluciona y se va perfeccionando progresivamente. En términos generales, una declaración de valor universal excepcional debe comprender una breve síntesis de los atributos y significación universal del bien, la justificación de los criterios que se utilizaron para su inclusión en la Lista, la declaración de integridad (para todos los bienes), la declaración de autenticidad (solo para aquellos propuestos con base a los criterios i a vi), y finalmente las prescripciones normativas para asegurar la eficacia y funcionalidad de los sistemas de protección y manejo del bien.

En el caso del Perú, se han aprobado declaraciones retrospectivas del valor universal excepcional para la Ciudad del Cusco, el Santuario Histórico de Machu Picchu, el Sitio Arqueológico de Chavín, el Parque Nacional de Huascarán, la Zona Arqueológica de Chan Chan, el Parque Nacional del Manu, el Centro Histórico de Lima, el Parque Nacional del Río Abiseo, las Líneas y Geoglifos de Nazca y Palpa y el Centro Histórico de Arequipa.

La eficacia y alcance de la protección que realiza el Comité del Patrimonio Mundial se puede observar con claridad en el caso del Santuario Histórico de Machu Picchu.

\section{Caso del Santuario Histórico de Machu Picchu}

Cuando el bien fue declarado patrimonio de la humanidad, el 09 de diciembre de 1983, no se hizo con una declaración específica de valor universal excepcional. Se utilizó una fundamentación de carácter cualitativo. En esa oportunidad, el ICOMOS estimó que no era necesaria una fundamentación de la inscripción porque los valores universales de Machu Picchu eran evidentes. Señaló que la “inscripción de Machu Picchu en la lista del 
patrimonio mundial se impone de manera evidente y torna impertinente y superflua cualquier justificación” (ICOMOS, 1983). El órgano consultivo, además de proclamar el valor universal excepcional de Machu Picchu como evidente, hizo una descripción histórica del Santuario y sus valores arquitectónicos, destacando la interrelación armoniosa y equilibrada entre la obra del hombre y la naturaleza, la planificación urbana de su construcción, su estado de conservación y la adecuación de la naturaleza a las funcionalidades de la ciudad a través de sus andenes o terrazas, "esculpidas literalmente en la montaña en la que construcciones ciclópeas parecen una continuidad de la naturaleza”.

En la 37 sesión del Comité del Patrimonio Mundial, llevada a cabo en la ciudad de Camboya, del 16 al 26 de junio de 2013, se aprobó la declaración retrospectiva de valor universal excepcional del Santuario Histórico de Machu Picchu a través de la resolución WHC-13/37.COM/8E. La declaratoria, hecha ya con los criterios técnicos definidos por las directrices operativas de la Convención, fundamenta el valor universal excepcional del bien y especifica el estado de las condiciones de integridad y autenticidad.

El Comité del Patrimonio Mundial, a partir del proyecto presentado por el Centro del Patrimonio Mundial e ICOMOS, sustentó la pertinencia del reconocimiento de valor universal excepcional en los criterios (i), (iii), (vii) y (ix), con la siguiente sustentación:

Criterio (i): La ciudad inca del Santuario Histórico de Machu Picchu es el centro estructurante de la naturaleza que lo rodea, una obra maestra artística, urbana, arquitectónica y técnica de la civilización inca. El acondicionamiento urbano de la montaña al pie del Huayna Picchu es el excepcional resultado de una integración con el medio ambiente, producto de un esfuerzo gigantezco que convierte a la ciudadela casi en una extensión de la naturaleza.

Criterio (iii): El Santuario Histórico de Machu Picchu es un testimonio único de la civilización inca que muestra una distribución de los espacios bien planificada, un control del territorio y una organización social, productiva, religiosa y administrativa.

Criterio (vii): Los remarcables monumentos y características históricas del Santuario de Machu Picchu están insertos en un paisaje de montaña espectacular de una belleza escénica y geomorfológica excepcional, lo que lo convierte en un ejemplo único de una relación permanente y armoniosa y de una belleza asombrosa entre la cultura humana y la naturaleza.

Criterio (ix): Cubriendo una parte del área de transición entre las alturas de los andes y la cuenca del Amazonas, el Santuario Histórico de Machu Picchu alberga una notable diversidad de microclimas de hábitats y de especies de flora y fauna con un alto grado de endemismo. El bien forma parte de un área mucho más amplia considerada unánimemente de importancia mundial para la preservación de la biodiversidad.

Se reconoció que la autenticidad del Santuario se ha preservado a lo largo del tiempo gracias a que se mantuvo aislado desde el siglo XVI y al hecho que, desde su redescubrimiento científico en 1911, las excavaciones arqueológicas y las tareas de conservación han sido realizadas respetando los estándares nacionales que han permitido mantener los atributos del bien. El Comité resaltó, asimismo, que: 
Con posterioridad al abandono del Santuario Histórico de Machu Picchu a inicios del siglo XVI, el crecimiento de la vegetación y el aislamiento han asegurado la conservación de los elementos estructurales del bien. No obstante que la concepción del lugar, los materiales y las estructuras hayan podido sufrir ligeras modificaciones debido a la degradación de las construcciones, las condiciones de autenticidad no han cambiado. Su redescubrimiento en 1911, las excavaciones arqueológicas y las ulteriores intervenciones de conservación han seguido las prácticas y las normas internacionales que han mantenido los atributos del bien. (ICOMOS, 1983)

Una apreciación similar realizó el Comité al fundamentar la presencia casi intacta de la condición de integridad de los elementos que conforman el Santuario, dentro de sus límites. Señaló el Comité que el sitio y su magnificente entorno natural se han preservado prácticamente intactos a través de los siglos. De manera complementaria adelantó -caso inusual en sus prácticas- que el bien podía ser extendido a Ollantaytambo, Pisac y el área concernida del Valle Sagrado, sin dejar de alertar sobre las amenazas que podían afectar al bien. Amerita recordar literalmente las expresiones del órgano rector del sistema al justificar la inscripción del Santuario en la Lista del Patrimonio Mundial:

El Santuario Histórico de Machu Picchu cumple con las condiciones de integridad porque los atributos naturales y humanos que encarnan su valor universal excepcional, presentes dentro de los límites del sitio, en su gran mayoría se encuentran preservados. El conjunto visual del sitio principal del Santuario Histórico de Machu Picchu -en su magnífico entorno montañoso- se ha mantenido casi intacto.

Sería deseable extender el bien, para incluir un conjunto aun más amplio de relaciones entre el hombre y la naturaleza, otros sitios culturales tales como Pisac y Ollantaytambo en el Valle Sagrado, así como una porción más grande de la cuenca del río Urubamba que también contribuirían a fortalecer la integridad del conjunto. Ello permitiría que el valor de la conservación de numerosas especies de bosque y de faunas raras y endémicas se beneficiaría de un estudio de manejo más profundo en las áreas adyacentes. Numerosas amenazas seriamente documentadas pueden provocar que se pierda la integridad del bien, por lo que se requiere una atención permanente de la administración.

El Comité, como se ha indicado, expresó su convicción de que los elementos del bien podían ampliarse a Ollantaytambo, Pisac y parte de la cuenca del Urubamba. Esta opinión implica el reconocimiento implícito del valor universal excepcional que presentan estos sitios. En la historia del patrimonio mundial, es el único caso en que el Comité de motu proprio ha postulado una extensión de esta naturaleza.

Sin embargo, más singular aun, podría ser el hecho que el Estado parte, el Perú, no haya adoptado hasta ahora ninguna iniciativa para concretar esta convicción del Comité del Patrimonio Mundial. Han pasado 35 años y el Estado peruano no ha tomado en cuenta esta predecisión del Comité, pues no ha elaborado el expediente respectivo para incluir en la Lista del Patrimonio Mundial estas expresiones invaluables de la cultura y la historia peruana, incluyendo su entorno natural. Inexplicablemente, la ciudad de Ollantaytambo y la zona arqueológica de Pisac no están incluidas siquiera en la lista tentativa del Perú. 
Los límites del Santuario en su conformación inicial, incluida la zona de amortiguamiento que definen con precisión los contornos del sitio, han sido aprobados y validados por el Comité:

Figura 1. Santuario Histórico de Machu Picchu.

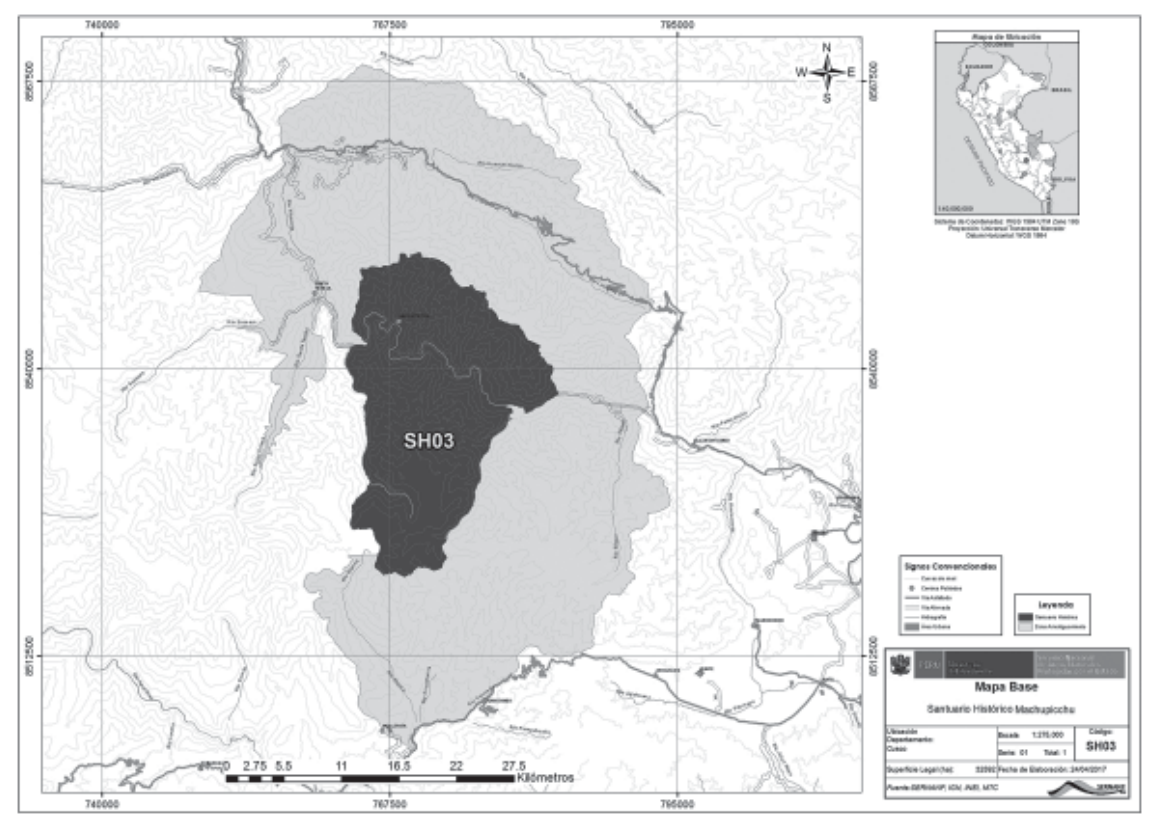

Las responsabilidades y obligaciones del Estado para preservar y proteger el VUE y las condiciones de autenticidad e integridad son exigibles, tanto en el área del Santuario propiamente dicha, como en la zona de amortiguamiento.

En la declaración retrospectiva del valor universal excepcional, el Comité expresó inquietudes, preocupaciones e hizo recomendaciones para que el Santuario tenga un sistema de gestión integrado, intersectorial y abierto a la participación de las comunidades locales. Señaló que las amenazas más importantes al Santuario estaban integradas por la degradación de los ecosistemas, la tala de árboles, el pillaje de plantas para la venta, la mala gestión de los desechos, la caza furtiva, la usurpación de tierras agrícolas, la contaminación del agua por desechos urbanos y productos agroquímicos vertidos en el río Urubamba.

En torno al turismo, se expresó su valor como una fuente de ingresos y, al mismo tiempo, como un agente que puede deteriorar y afectar el bien en ausencia de una regulación adecuada.

Más allá de estas observaciones, el Comité centró su preocupación en la necesidad de que el Perú establezca un sistema de gestión integrado que supere el fraccionamiento de las competencias y administración del Santuario, y que permita aplicar un plan de gestión viable y eficaz.

Solo 16 años después de inscrito el bien se pudo establecer, en 1999, una unidad de gestión del Santuario, la misma que tuvo un funcionamiento intermitente. El 2011, atendiendo a las reiteradas preocupaciones, llamamientos 
y recomendaciones del Comité, se reactivó la Unidad de Gestión con representantes de los ministerios de Cultura, Medio Ambiente, Relaciones Exteriores y Turismo, el Gobierno Regional del Cusco -que preside el Comité ejecutivo de la Unidad de Gestión- y la Municipalidad distrital de Machu Picchu.

Por deficiencias en la estructura de la Unidad de Gestión y en su funcionamiento, una permanente dificultad para integrar verticalmente las decisiones del aparato del Estado, la ausencia de procesos de concertación adecuados con las colectividades locales, las limitaciones de la legislación nacional en torno a la protección del Santuario que, si bien ha hecho avances notables, sigue siendo insuficiente, como en el caso del ordenamiento urbano de Machu Picchu pueblo, así como por una ostensible demora en la adopción de decisiones para aprobar y ejecutar el plan maestro de gestión, establecer un plan de desarrollo turístico sostenible, resolver los problemas de capacidad de carga ya en estado de saturación y por una incomprensible resistencia de algunos actores al establecimiento de un centro de visitantes e interpretación, el Santuario en varias oportunidades ha estado a punto de ser incluido en la lista de bienes en peligro.

Con la finalidad de cooperar con el Estado peruano, de evaluar en el terreno la persistencia de los problemas de gestión y de los factores que afectan al bien, el Comité del Patrimonio Mundial ha enviado cinco misiones de monitoreo (1997, 1999, 2002, 2003 y 2012).

Debido a la persistencia de los problemas, en dos oportunidades (2007 y 2017) el Comité dispuso el viaje al Santuario de dos misiones de monitoreo reactivo, que son aquellas que se deciden cuando el bien enfrenta un peligro real de pérdida o afectación del valor universal excepcional. Cuando las recomendaciones de las misiones de monitoreo reactivo no se cumplen o persisten las amenazas al VUE del bien, para evitar el deterioro o el empeoramiento de la situación, el Comité decide la inclusión del bien en la Lista del Patrimonio Mundial en peligro. El Comité, al decidir las misiones de monitoreo reactivo en Machu Picchu, las estableció como un paso previo a una eventual decisión de pasar el bien a la lista en peligro.

Entre el año 2012 y la actualidad se han hecho avances importantes en la estructura y la eficacia de la gestión del Santuario y ello ha permitido, por el momento, que el Comité haya descartado la eventual inscripción en la lista en peligro. El mantenimiento y consolidación de esta decisión dependerá de la manera cómo la Unidad de Gestión del Santuario ejecute las recomendaciones del Comité, concertadas con el Estado peruano.

Estas recomendaciones se refieren básicamente a las siguientes cuestiones pendientes:

1. En el ámbito de la gestión:

a. Orientar la gestión del bien a través de una visión global basada en el VUE, más que en requerimientos exclusivos del turismo y vincularla a un sistema integral de monitoreo con indicadores definidos, con el fin de identificar con antelación nuevas amenazas.

b. Finalizar la aprobación del nuevo reglamento de la Unidad de Gestión de Machu Picchu.

c. Definir los indicadores indispensables para la elaboración y puesta en práctica de un sistema integral de monitoreo. 
d. Vincular la zona de Santa Teresa con el plan de acceso amazónico y la gestión del bien, incorporándolo efectivamente en la estructura orgánica de la UGM.

e. Desarrollar reglamentos de uso sostenible, y sus respectivas sanciones, para otros tipos de uso que van más allá del turístico (en conformidad con los tipos de uso establecidos en el plan de uso público y plan de manejo del Santuario).

2. En torno a la estrategia turística:

a. Definir de la capacidad de carga para la Llaqta y para el Camino Inca, basada principalmente en objetivos de conservación. Un nuevo estudio de capacidad de carga será necesario conforme a los requerimientos de la Convención del Patrimonio Mundial.

b. Aplicar límites claros para el número de visitantes.

c. Proponer planes de diferenciación de flujos de visitantes, vinculando en el proceso a las empresas de transporte colectivo y tren.

d. Promoción de sitios de visita alternativos fuera de la Llaqta.

e. Iniciar sin demora la ejecución del proyecto del centro de visitantes Puente Ruinas.

3. En relación con la estrategia integral del acceso amazónico:

a. Evaluar la mejora física y posibles cambios en la gestión en el punto de control del km 122.

b. Aprobar el plan del sitio Aobamba-Puente Ruinas y aplicar sus reglamentos.

c. Regular el tipo de construcciones y licencias de construcción a lo largo de la ruta de senderismo y en la parada del tren.

d. La conveniencia de incluir un plan para un segundo centro de visitantes en el plan de desarrollo del acceso amazónico.

4. En lo que concierne al ordenamiento urbano de Machu Picchu pueblo:

a. Guiar las obras de construcción de la conexión entre Machu Picchu pueblo y Puente Ruinas (Alameda de Machu Picchu) en conformidad con la Nota del Consejo del Patrimonio Mundial de la UICN sobre evaluación ambiental y la Guía del ICOMOS (2011) sobre las evaluaciones de impacto del patrimonio para los bienes del patrimonio mundial cultural.

b. Utilizar técnicas de construcción y materiales de construcción más adaptados y menos impactantes, como por ejemplo mantener el "camino de tierra”, utilizar estructuras de madera y acero para la vía peatonal y miradores, techos en tejas artesanales y evitar el uso de hormigón. 
5. Sobre la proyectada reserva de biosfera Machu Picchu-Choquequirao:

a. Implementar el plan de trabajo 2017 de desarrollo de la propuesta de reserva de biosfera, otorgando la máxima prioridad a la promoción de la expresión de la OUV del bien y la consulta y socialización con las partes interesadas.

6. Sobre los proyectos de desarrollo en ejecución y los previstos:

a. Conforme al párrafo 172 de las directrices prácticas, presentar al Centro del Patrimonio Mundial información detallada sobre los nuevos proyectos en la zona, tales como el aeropuerto internacional de Chinchero, el aeródromo de Quillabamba, el teleférico de Choquequirao y el proyecto para el segundo centro de visitantes. Asegurar que dichos proyectos sean evaluados rigurosamente en términos de su impacto en el VUE del sitio.

7. En lo referente a la ejecución de la Decisión 41 COM 7B.36 del Comité del Patrimonio Mundial:

a. Revisar las capacidades de carga sobre la base de las necesidades de conservación y la aplicación de límites claros a los visitantes.

b. Desarrollar regulaciones y sanciones para otros tipos de usos más allá del turismo.

c. Asegurar que los desarrollos propuestos se evalúen rigurosamente en términos de su impacto en el VUE, de manera compatible con la Nota de Consejo de Patrimonio Mundial de la UICN sobre evaluación ambiental y la Guía del ICOMOS sobre las evaluaciones de impacto del patrimonio para los bienes del patrimonio mundial cultural.

Otro de los mecanismos de protección aplicado al caso de Machu Picchu es el de la cooperación financiera. El Perú ha recibido 166625 dólares no reembolsables para el financiamiento de cursos de capacitación, entrenamiento, preparación del plan maestro de gestión, pago de consultorías, y otras actividades relativas a la preservación del Santuario.

En los 35 años que el Santuario Histórico de Machu Picchu está sujeto al sistema internacional de protección, se ha logrado avances importantes en la gestión, preservación y conservación del sitio. En ese período se ha incrementado también de manera exponencial el turismo. Lo que implica nuevos desafíos y retos para una gestión sostenible. Machu Picchu se ha posicionado en el mundo entero como ícono de la institución del patrimonio mundial. Y ello, sin costos financieros mayores para el Estado peruano, ha sido y es el principal factor difusor para el turismo en el Perú. La responsabilidad del Estado y la sociedad es asegurar que el Santuario se transmita de generación en generación sin afectar su valor universal excepcional y sus extraordinarias condiciones de autenticidad e integridad. Luego de tres décadas y media, parece haber llegado el momento de que las autoridades gubernamentales locales y los actores sociales e institucionales vinculados a la Llaqta, comprendan que, en el caso de Machu Picchu, el turismo y la preservación del patrimonio son dos dimensiones de una sola realidad. El turismo debe contribuir y constituirse en un medio de protección y preservación. Y estos, cuanto más sean respetados, incidirán en el efecto multiplicador del turismo sostenible. 
Para ello es indispensable que avances realizados como el reforzamiento de la unidad de gestión, los estudios de armonización de los instrumentos legales que regulan las actividades en el Santuario, la aprobación de una estrategia comprensiva para el acceso occidental al Santuario, la aprobación del plan de uso público, las resoluciones ministeriales destinadas a regular el turismo en la Llaqta y en el Camino del Inca, la aprobación del estudio de capacidad de carga del 2016, la aprobación del plan urbano del distrito de Machu Picchu y el estudio de prevención de riesgos, entre otros aspectos positivos, deben ser complementados necesariamente con la ejecución eficaz e inmediata de las recomendaciones centrales del Comité del Patrimonio Mundial, especialmente las relativas a la ampliación del ámbito espacial y los referentes turísticos en la Llaqta, la fijación de un límite al número de visitantes dentro de esta nueva concepción, el establecimiento del centro de visitantes, y la adecuación de las estructuras urbanas del distrito de Machu Picchu para eliminar definitivamente la contaminación visual.

La eficacia del sistema de protección internacional de Machu Picchu presenta un saldo positivo. No obstante las insuficiencias subsistentes en la gestión del Santuario, algunas muy serias, ha contribuido a su preservación y, sobre todo, ha permitido detener, evitar o minimizar decisiones, acciones, situaciones y procesos adoptados en el ámbito interno que han podido afectar irremediablemente su valor universal excepcional.

\section{El turismo y el patrimonio cultural y natural}

Por estas razones, el turismo que se desarrolla en el Perú con cierta intensidad a partir de la tercera década del siglo XX, es esencialmente un turismo cultural e histórico. Un turismo de patrimonio cultural, que va desde Machu Picchu, los centros históricos del Cusco o Arequipa, o la reserva del Manu hasta la Fiesta del Inti Raymi, la Festividad de la Candelaria, las prácticas y saberes culinarios de las cocinas peruanas o el avistamiento de aves.

Las estadísticas del turismo en el Perú confirman esta aseveración. Conforme a los datos de PROMPERU (2015), el año 2014 prácticamente el 100\% de turistas extranjeros que llegaron al Perú por vacaciones (62\% del turismo receptivo) lo hizo motivado para visitar o conocer sitios o expresiones del patrimonio cultural y natural del Perú. 78\% para visitar Machu Picchu (patrimonio cultural y natural de la humanidad, 1983), 52\% para ir al Centro Histórico de la Ciudad del Cusco (patrimonio cultural de la humanidad, 1983), 45\% al Centro Histórico de Lima (patrimonio cultural de la humanidad, 1988-1991), 20\% a sitios o restos arqueológicos diferentes a Machu Picchu (el Sitio Arqueológico de Chavín fue declarado patrimonio cultural de la humanidad en 1995, la Ciudad Sagrada de Caral en el 2009, las Líneas de Nazca en 1994, y la Zona Arqueológica de Chan Chan está inscrita en la lista en peligro del patrimonio cultural de la humanidad desde 1986); 16\% por la comida peruana, (los saberes y prácticas de la cocina peruana son patrimonio inmaterial de la nación y deben declararse patrimonio cultural inmaterial de la humanidad); 13\% para visitar el Lago Titicaca (la Festividad de la Virgen de la Candelaria es patrimonio cultural inmaterial de la humanidad desde el 2015, y el arte textil de Taquile desde el 2008); 6\% para visitar el Centro Histórico de Arequipa (patrimonio cultural de la humanidad desde el 2000); 5\% para visitar el Qhapaq Ñan (patrimonio cultural desde el 2014); y el 4\% para ir a las Líneas de Nazca (patrimonio cultural desde 1994) (PROMPERU, 2015, pp. 24-25). 
El turismo extranjero casi en su totalidad, y gran parte del turismo nacional, están vinculados con el patrimonio cultural y natural del Perú, que es la oferta turística que domina el mercado y que corresponde también a la demanda de los visitantes. En ese contexto, el Estado, las instituciones, las empresas turísticas, los usuarios, los consumidores y las universidades -como generadoras y difusoras del conocimiento- deben actuar para preservar el patrimonio cultural y natural y asegurar modelos de uso y gestión sostenible para la industria del turismo.

\section{Referencias}

Bories, C. (2011). Le patrimoine culturel en droit international. París: Pedone.

Convención de Viena sobre Derecho de los Tratados. (23 de mayo de 1969). Preámbulo.

Cooperación Española. (2018). Provisión de bienes públicos globales. Recuperado de http://www.cooperacionespanola.es/es/provisionde-bienes-publicos-globales

Corte Internacional de Justicia - CIJ. Demanda del Perú sobre la controversia marítima con Chile. Recuperado de www.cij.com

González, J. D., Sánchez, U. I., \& Sáenz, P. A. (1998). Derecho internacional público. Madrid: Civitas.

ICOMOS. (21 de junio de 1983). Recomendación para la inscripción del Santuario de Machu Picchu en la Lista del Patrimonio Mundial. ICOMOS.

ICOMOS. (2011). Guidance on Heritage Impact Assessments for Cultural World Heritage Properties. París: ICOMOS.

Kaul, I., Grunberg, I., \& Stern, M. A. (Edits.) (1999). Bienes públicos mundiales. Nueva York: PNUD, Oxford University Press.

Ministerio de Justicia. (2003). Constitución política del Perú. Lima: Ministerio de Justicia .

PROMPERÚ. (2015). Perfil del turista extranjero 2014. Lima: PROMPERÚ.

Reurter, P. (1985). Introducción al derecho de los tratados. México: Fondo de Cultura Económica.

Rodríguez, M. (2010). La soberanía marítima del Perú. Lima: Derrama Magisterial.

T.P.J.I. Serie A, núm. 9, p. 27.

T.P.J.I. Serie B, núm.10, p. 20.

T.P.J.I. Serie A/B, núm. 44, p. 24.

UNESCO. (2006). Textos básicos de la convención del patrimonio mundial de 1972. París: Unesco.

UNESCO. (2008). Directrices prácticas para la aplicación de la convención del patrimonio mundial. París: Centro del Patrimonio Mundial de la Unesco.

Manuel Rodríguez Cuadros

Embajador, jurista y ensayista, Ministro de Relaciones Exteriores (2003-2005), profesor universitario, Presidente del Comité del Patrimonio Mundial Inmaterial (2016), Presidente de la Conferencia de los Estados parte de la Convención del Patrimonio Mundial Inmaterial (2016), Vicepresidente del Comité del Patrimonio Mundial (20152017), Presidente del Instituto de Derecho Internacional y Relaciones Internacionales (ILADIR), Representante Permanente del Perú ante la UNESCO. 